\title{
Constitucionalismo global, control de convencionalidad y el derecho a huelga en Chile $^{*}$
}

Fecha de recepción: 9 de enero de 2015

Fecha de aceptación: 14 de septiembre de 2015

Doi: dx.doi.org/10.12804/acdi9.1.2016.04

\section{Gonzalo Aguilar Cavallo**}

Resumen: En el ámbito interamericano, el control de convencionalidad impulsado por la Corte Interamericana de Derechos Humanos ha sido vinculado con el proceso de construcción de un ius commune en derechos humanos. Los derechos humanos han sido identificados como normas de carácter constitucional. La universalidad de los derechos humanos contribuye a su determinación como un aspecto del constitucionalismo global. Este trabajo tiene por objetivo examinar si el control de convencionalidad puede ser considerado una manifestación del constitucionalismo global en el específico ámbito interamericano. Nuestra hipótesis es que el control de convencionalidad ha potenciado la aplicación de un estándar mínimo de

* Este trabajo se inserta en la ejecución del proyecto de investigación No DI-539-14/ JM de la Dirección General de Investigación y Desarrollo de la Universidad Andrés Bello. ** Abogado (Chile); doctor en Derecho (España); magíster en Relaciones Internacionales (España); máster en Derechos Humanos y Derecho Humanitario (Francia); posdoctorado en el Max Planck Institute for Comparative Public Law and International Law (Heidelberg, Alemania). Profesor de Derecho Constitucional, Internacional y Derechos Humanos dela Universidad de Talca (Chile); Director del Magister en Derecho Constitucional del Centro de Estudios Constitucionales de Chile de la Universidad de Talca-Campus Santiago. Correo electrónico:gaguilarch@hotmail.com

Para citar este artículo: Aguilar Cavallo, Gonzalo, "Constitucionalismo global, control de convencionalidad y el derecho a huelga en Chile", Anuario Colombiano de Derecho Internacional (ACDI), 2016, 9, pp. 113-166. Doi: dx.doi.org/10.12804/acdi9.1.2016.04 
derechos humanos y que, junto con el principio pro homine, ha estimulado la emergencia de un ius commune en derechos humanos.

Palabras clave: Corte Interamericana de Derechos Humanos, derecho internacional de los derechos humanos, control de convencionalidad, ius commune interamericanum, constitucionalismo global.

\section{Global Constitutionalism, Control of Conventionality and the Right to Strike in Chile}

Abstract: In the Inter-American context, the control of conventionality promoted by the Inter-American Court of Human Rights is linked to the process of construction of an ius commune in human rights. Human rights are identified as norm of constitutional character. The universality of human rights allows its consideration as an aspect of global constitutionalism. This paper aims at determining whether the control of conventionality can be considered an expression of global constitutionalism within the Inter-American region. We hold that the control of conventionality in the Inter-American system has propelled the application of a minimum standard of human rights and has stimulated the emergence of an ius commune in human rights.

Keywords: Inter-american Commission on Human Rights, International Human Rights Law, Control of Conventionality, ius commune interamericanum, Global Constitutionalism

Constitucionalismo global, controle de convencionalidade e o direito a greve no Chile

Resumo: No âmbito interamericano, o controle de convencionalidade impulsado pela Corte Interamericana de Direitos Humanos tem sido vinculado com o processo de construção de um ius commune em direitos humanos. Os direitos humanos têm sido identificados como normas de carácter constitucional. A universalidade dos direitos humanos contribui a sua determinação como um aspecto do constitucionalismo global. Este trabalho tem por objetivo examinar se o controle de convencionalidade pode ser considerado uma manifestação do constitucionalismo global no 
específico âmbito interamericano. Nossa hipótese é que o controle de convencionalidade tem potenciado a aplicação de um standard mínimo de direitos humanos e que junto com o princípio pro homine, tem estimulado a emergência de um ius commune em direitos humanos.

Palavras-chave: Corte Interamericana de Direitos Humanos, direito internacional dos direitos humanos, controle de convencionalidade, ius commune interamericanum, constitucionalismo global.

"Una vez que las ideas han sido revolucionadas, la realidad ya no puede oponer resistencia". Georg Hegel ${ }^{1}$

\section{Introducción}

La interrogante que se plantea en este estudio es, si en el ámbito interamericano el control de convencionalidad puede ser considerado una expresión concreta de un constitucionalismo global, y específicamente de un ius constitutionale commune interamericanum. El control de convencionalidad habría potenciado el debate y la disposición de los órganos jurisdiccionales internos e internacionales de derechos humanos hacia un diálogo entre jueces. A través de este diálogo se construiría este ius commune interamericanum. En este sentido, nos interesa a modo de ejemplo, mencionar casos recientes muy relevantes sobre el derecho humano a la huelga en Chile.

En este contexto, las preguntas que se formulan en esta investigación son: ¿puede el control de convencionalidad ser una de las manifestaciones actuales del proceso de construcción de un ius commune interamericanum? ¿Cuál es el papel que juega el diálogo entre jueces en este proceso de construcción de un ius commune interamericanum? ¿Cuál es la relación entre control de convencionalidad y diálogo entre jueces? ¿Pueden encontrarse ejemplos nacionales de control de convencionalidad en relación con casos vinculados a derechos sociales? Consecuentemente, el objetivo de este estudio consiste en determinar si se puede considerar al control de

Así, Herz cita a Hegel sin una referencia. Herz, John, "Rise and demise of the territorial State”, World Politics, 1957, 9, pp. 473-493. 
convencionalidad como una expresión de un ius commune interamericanum. Además, a través del análisis de un caso de derechos sociales, se pretende establecer si el rol del juez y el diálogo son una vía que contribuye a la construcción de un ius commune. Nuestra hipótesis es que el control de convencionalidad, sin ser una innovación desde el punto de vista de las obligaciones para los Estados, ha potenciado, en los Estados sujetos a la jurisdicción de la Corte Interamericana de Derechos Humanos (en adelante, Corte IDH), la aplicación de un estándar mínimo de derechos humanos, el que, junto con el principio pro homine, ha estimulado la emergencia de un ius commune en derechos humanos, contribuyendo - al menos en este aspecto y en este ámbito geográfico- a la concretización de un constitucionalismo global. El método que se utilizará en este trabajo será el análisis dogmático jurídico y la técnica de revisión documental, en una primera parte, y luego, el método de casos, en una segunda parte. Desde el punto de vista metodológico, conviene desde ya aclarar que el análisis que se hará de un ius commune interamericanum se concentra específicamente en el área de los derechos humanos. Así, desde un comienzo, debe tenerse presente que nosotros consideramos que los derechos humanos constituyen componentes jurídicos fundamentales de todo orden constitucional.

Consecuentemente, en una primera parte abordaremos las principales características del constitucionalismo global. En una segunda parte, examinaremos la noción de ius commune interamericanum. En una tercera sección, analizaremos la noción de control de convencionalidad y su relación con el constitucionalismo global. Finalmente, enfocaremos nuestro estudio en un caso de derechos sociales que podría ser usado como ejemplo de control de convencionalidad y una manifestación de constitucionalismo global.

\section{Constitucionalismo global}

Existen distintas interpretaciones acerca del constitucionalismo global. Sin embargo, antes de abordar estas distintas interpretaciones, conviene previamente discutir acerca del sentido del constitucionalismo. En esta línea, nos es útil comenzar con una de las cuatro nociones de constitucionalismo ofrecidas por Paul Craig, la cual es, según este autor, muy común en el ámbito del derecho público. Así, constitucionalismo

[e]s usado para expresar no sólo si el sistema jurídico tiene los rasgos característicos de una Constitución, sino también la medida en la cual satisface preceptos deseables de buena gobernanza, lo cual va más 
allá de lo normalmente expresado dentro de la misma Constitución. Cuestiones tales como la responsabilidad del gobierno, ampliamente entendida, principios de buena administración y de incorporación de los derechos humanos, son mencionados, por ejemplo, como expresión de una cultura de constitucionalismo. ${ }^{2}$

Por su parte, Luis Fernando Angulo ha señalado que "el constitucionalismo se presenta como un fenómeno social que bien representa la etapa superior de una dialéctica histórica, o como la expresión de una serie de valores y reglas inherentes a las sociedades modernas". ${ }^{3}$ En este contexto, también se ha propuesto, como una conceptualización del constitucionalismo contemporáneo, el compromiso creciente de los gobiernos con los principios de los derechos humanos, el Estado de derecho, los ideales de transparencia, gobierno responsable y democrático, y con el adecuado funcionamiento del sistema de justicia. ${ }^{4}$ En esta línea, específicamente en cuanto al Estado de derecho, las Naciones Unidas lo define como:

un principio de gobierno según el cual todas las personas, instituciones y entidades, públicas y privadas, incluido el propio Estado, están sometidas a unas leyes que se promulgan públicamente, se hacen cumplir por igual y se aplican con independencia, además de ser compatibles con las normas y los principios internacionales de derechos humanos. Asimismo, exige que se adopten medidas para garantizar el respeto de los principios de primacía de la ley, igualdad ante la ley, rendición de cuentas ante la ley, equidad en la aplicación de la ley, separación de poderes, participación en la adopción de decisiones, legalidad, no arbitrariedad, y transparencia procesal y legal. ${ }^{5}$

2 Craig, Paul, "Constitution, constitutionalism and the European Union", European Law Journal, 2001, 7, (2), pp. 125-150, especialmente p. 128.

3 Angulo Jacobo, Luis Fernando, Constitucionalismo global, p. 12, en https://www.scjn. gob.mx/Transparencia/Lists/Becarios/Attachments/44/Becarios_044.pdf, consulta del 20 de noviembre de 2014.

4 Manga Fombad, Charles, "The context of justice in Africa: emerging trends and prospects", in UNDP: retbinking the role of law and justice in Africa's development, an edited volume of discussion papers, United Nations Development Programme, 2013, p. 3. (T. del A.).

5 Asamblea General, En aras de la justicia: un programa de acción para reforzar el estado de derecho en los planos nacional e internacional, informe del Secretario General, Doc. N.U. A/66/749, 16 de marzo de 2012, para. 2. 
Desde la perspectiva internacional, según Anne Peters, “el constitucionalismo global es una agenda política y académica que identifica y aboga por la aplicación de principios constitucionalistas en la esfera jurídica internacional para mejorar la efectividad y la justicia del orden jurídico internacional". ${ }^{6}$ ¿Cuáles serían estos principios constitucionales aplicables a la esfera internacional? Astrid Epiney identifica los siguientes: 1) respeto de los derechos fundamentales de los individuos, 2) legitimación del ejercicio del poder, 3) respeto del principio de Estado de derecho y 4) protección jurídica eficaz y defensa de los derechos de los individuos. ${ }^{7}$ En este sentido, Peter Häberle ha indicado que "los elementos constitutivos del Estado constitucional (como los procedimientos democráticos, la independencia de la jurisdicción, los derechos humanos) pueden ser 'exportados', a fin de constituir a la comunidad de los Estados". ${ }^{8}$ Por su parte, Ahmed Mahiou ha afirmado que la idea de la constitucionalización del derecho internacional remonta a la Primera Guerra Mundial, con autores como Paul Otlet y George Scelles, y reforzado después de la Segunda Guerra Mundial bajo la inspiración de un análisis constitucionalista del derecho internacional, fomentado por el estatus y el carácter innovador de la Carta de las Naciones Unidas. ${ }^{9}$ Además, la Corte Internacional de Justicia ha usado el término Constitución poniendo el acento en el criterio material de definición de la Constitución. ${ }^{10}$ De acuerdo con Epiney, "la mundialización del derecho es ante todo un problema de buen gobierno a nivel internacional: en la medida en que los principios constitucionales evocados sobrepasan el nivel estatal, se hace necesario constitucionalizar el derecho internacional público", o bien, proceder a la constitucionalización

\footnotetext{
6 Peters, Anne, “The merits of global constitutionalism”, Indiana Journal of Global Legal Studies, 2009, 16, (2), pp. 397-411.

7 Epiney, Astrid, «Européanisation et mondialisation du droit: convergences et divergences», en Morand, Charles-Albert (Dir.), Le droit saisi par la mondialisation, Bruylant, Bruxelles, 2001, pp. 147-170, especialmente pp. 162-163.

8 Häberle, Peter, ElEstado constitucional, traducción de Héctor Fix-Fierro, UNAM-Instituto de Investigaciones Jurídicas, México, 2003, p. 69.

9 Mahiou, Ahmed, «Le droit international ou la dialectique de la rigueur et de la flexibilité. Cours général de droit international public», Recueil des Cours, 2008, 337, pp. 9-516, especialmente pp. 64 a 66.

10 ICJ, Legality of the use by a State of nuclear weapons in armed conflict, Advisory opinion of 8 July 1996, ICJ Reports 1996, p. 66, para. 19.
} 
de la mundialización (globalización) del derecho. ${ }^{11}$ En esta línea, Miguel Carbonell remarca — correctamente a nuestro entender- que "la noción misma de 'constitucionalismo global' indica la necesidad de prescindir de las fronteras, al menos tal y como se las entiende actualmente, para avanzar hacia una protección universal de los derechos fundamentales [...]". ${ }^{12} \mathrm{La}$ cuestión de la mundialización o globalización del derecho no es igual que la internacionalización del derecho. La mundialización o globalización del derecho se plantea en un contexto mucho más amplio y no se limita a las influencias del derecho internacional, sino que también engloba los efectos de la mundialización y de sus mecanismos, sobre los órdenes jurídicos nacionales. ${ }^{13}$

Desde el punto de vista interno de los Estados, el constitucionalismo global es un fenómeno que responde al nuevo paradigma constitucional. Este constitucionalismo, propio de la época actual, presenta algunas características básicas:

1) El constitucionalismo global responde a tres pilares fundamentales, los cuales constituirían el sustratum moderno del constitucionalismo: democracia, derechos humanos y Estado de derecho.

2) El constitucionalismo actual se ve estimulado por un Estado abierto. El Estado constitucional democrático de nuevo cuño del siglo XXI es un Estado abierto al razonamiento jurídico global, especialmente en materia de derechos humanos, lo que tiene la virtualidad de forjar un nuevo derecho público. Así, Häberle ha sostenido que "[l] a 'sociedad abierta' merece tal calificativo solamente si es una sociedad abierta hacia lo internacional. Los derechos fundamentales y humanos remiten al Estado y a 'sus' ciudadanos también hacia lo 'otro', lo 'extraño', es decir, a otros Estados con sus sociedades y a los ciudadanos 'extranjeros". ${ }^{14} \mathrm{La}$ apertura de este Estado constitucional opera como herramienta de construcción de ese nuevo derecho público, particularmente

\footnotetext{
11 Epiney, «Européanisation et mondialisation...», op. cit., p. 164.

12 Carbonell, Miguel, “Derecho a migrar”, en Fix-Zamudio, Héctor y Valadés, Diego, Instituciones sociales en el constitucionalismo contemporáneo, Instituto de Investigaciones Jurídicas, México, 2011, pp. 59-68, especialmente p. 63.

13 Epiney, «Européanisation et mondialisation...», op. cit., p. 148.

14 Häberle, El Estado constitucional, op. cit., p. 68.
} 
a través del derecho internacional de los derechos humanos y del uso del derecho comparado. En este sentido, las cláusulas de apertura que menciona Héctor Fix-Zamudio son especialmente útiles. ${ }^{15} \mathrm{Y}$ por otro lado, la particular disposición de un juez avezado, inserto en el mundo, con conocimientos y destrezas necesarias en un mundo integrado, transnacional y multicultural, aporta también para que, mediante el derecho comparado, se incorporen interpretaciones, argumentos y razonamientos jurídicos, en un diálogo, cuyo fin es la mejor protección del individuo, comunidades y pueblos, y de sus derechos. ${ }^{16}$ En este sentido, Armin von Bogdandy señala que "el concepto de un derecho común latinoamericano tiene la convicción de que es necesario que el Estado esté abierto al derecho internacional, a las instituciones internacionales, así como a la comparación jurídica como herramienta decisiva para el progreso". ${ }^{17}$

Este Estado abierto genera un cambio de paradigma en el derecho público porque altera el entendimiento tradicional de uno de los conceptos básicos del derecho, esto es, la soberanía. En esta línea, Von Bogdandy afirma que "[1]a apertura y la globalización socavan la famosa premisa del principio clásico de soberanía según la cual los estados son 'comunidades independientes". ${ }^{18}$ En efecto, el nuevo paradigma en el derecho público

15 "En una época reciente se observa la tendencia en algunas constituciones latinoamericanas, tanto para superar la desconfianza tradicional hacia los instrumentos internacionales y en general hacia el derecho internacional, como para introducir de manera paulatina una cierta preeminencia, así sea cautelosa, de las normas de carácter supranacional". Fix-Zamudio, Héctor, "El derecho internacional de los derechos humanos en las constituciones latinoamericanas y en la Corte Interamericana de Derechos Humanos", Revista Latinoamericana de Derecho, 2004, I, (1), pp. 141-180, especialmente p. 147.

16 Reina García, Óscar M., "Las cláusulas de apertura o reenvío hacia fuentes externas previstas en la Constitución colombiana, como criterio para delimitar el contenido del bloque de constitucionalidad”, Revista Derecho del Estado, 2012, (29), pp. 175-214.

17 Von Bogdandy, Armin, "Ius constitutionale commune latinoamericanum. Una aclaración conceptual", en Von Bogdandy, Armin; Fix-Fierro, Héctor \& Morales Antoniazzi, Mariela (Coords.), Ius constitutionale commune en América Latina. Rasgos, potencialidades y desafíos, Instituto de Investigaciones Jurídicas, Instituto Max Planck de Derecho Público Comparado y Derecho Internacional, Instituto Iberoamericano de Derecho Constitucional, UNAM-IIJ, México, 2014, pp. 3-23, especialmente p. 9.

18 Ibíd., p. 6. 
altera la lógica soberanista clásica de la summa potestas y plenitudo potestatis. ${ }^{19}$ De este modo, algunas características relevantes de la soberanía, en el nuevo derecho público, podrían ser las siguientes:

a) La soberanía se encuentra sujeta a los derechos humanos, tanto de fuente nacional como internacional. En el caso de la Carta de los Derechos Fundamentales de la Unión Europea (Niza, 2000), esta sujeción sería a fuentes de carácter incluso supranacional. En este contexto, el entendimiento e interpretación de los derechos humanos que debería primar no se determina por una regla formal de solución de conflictos normativos, sino más bien por un principio material del derecho que prefiere el contenido normativo que mejor proteja al ser humano y sus derechos o que menos los restrinja.

b) La soberanía se encuentra limitada por los intereses esenciales de la comunidad internacional en su conjunto.

c) Hay normas que se imponen a los Estados aun sin su consentimiento. ${ }^{20}$ Estas son las denominadas normas inderogables.

d) El principio del primado del derecho, lato sensu, por sobre la política y la decisión política. Christian Tomuschat indica que el principio implicado en este desarrollo puede comprenderse fácilmente. El alcance de los dos principales instrumentos de

19 Sobre el significado original de estas nociones, ver Kritsch, Raquel, "Fundamentos históricos e teóricos da noçào de soberanía: a contribuçao dos 'Papas juristas' do século XIII", Estudios Históricos, 2010, 23, (46), pp. 261-279.

20 "The origins and character of that Convention, the objects pursued by the General Assembly and the contracting parties, the relations which exist between the provisions of the Convention, inter se, and between those provisions and these objects, furnish elements of interpretation of the will of the General Assembly and the parties. The origins of the Convention show that it was the intention of the United Nations to condemn and punish genocide as 'a crime under international law' involving a denial of the right of existence of entire human groups, a denial which shocks the conscience of mankind and results in great losses to bumanity, and which is contrary to moral law and to the spirit and aims of the United Nations (Resolution 96 1) of the General Assembly, December 11 th 1946). The first consequence arising from this conception is that the principles underlying the Convention are principles which are recognized by civilized nations as binding on States, even without any conventional obligation. A second consequence is the universal character both of the condemnation of genocide and of the CO-operation required in order to liberate mankind from such an odious scourge' (Preamble to the Convention). The Genocide Convention was therefore intended by the General Assembly and by the contracting parties to be definitely universal in scope". ICJ, Reservations to the Convention on the Prevention and Punishment of the Crime of Genocide, Advisory opinion of May 28 ${ }^{\text {th }}$, 1951, ICJ Reports 1951, p. 15, p. 23. 
derechos humanos de las Naciones Unidas es tan amplio que casi ninguna decisión política a nivel nacional queda al margen del alcance del derecho internacional. ${ }^{21}$ Luego de la Declaración Universal de los Derechos Humanos, los principales instrumentos de derechos humanos son el Pacto Internacional de Derechos Económicos, Sociales y Culturales, y el Pacto Internacional de Derechos Civiles y Políticos, ambos de 1966.

e) Los elementos fundantes básicos del nuevo derecho público, a saber, la democracia, el Estado de derecho y los derechos humanos, son elementos de carácter constitucional y debieran estar a la base de la constitución de toda comunidad humana. ${ }^{22}$ En este sentido, Carbonell señala que "[e]l constitucionalismo global (también llamado cosmopolitismo constitucional) toma en consideración la necesidad de abrir las fronteras a los derechos [...]" ${ }^{23}$ De este modo, sería pensable la aplicación de estos elementos constitucionales a una comunidad que trascendiera las fronteras de un Estado. Este proceso de aplicación de elementos de naturaleza constitucional en forma transversal a los Estados, eventualmente, podría llamarse constitucionalismo transnacional. ${ }^{24}$ Por su lado, Marcelo Neves indica que "el transconstitucionalismo no toma un único orden o un determinado tipo de orden como punto de partida o última ratio. Busca lanzar 'puentes' de transición, de promoción de 'conversaciones constitucionales', de fortalecimiento de los lazos constitucionales

21 Tomuschat, Christian, "International law: ensuring the survival of mankind on the eve of a new century. General course on public international law", Recueil des Cours, 1999, 281, pp. 9-438, especialmente p. 64.

22 Craig, "Constitution, constitutionalism...," op. cit., p. 128; Tomuschat, "International law...", ibíd.; Von Bogdandy, Armin, Hacia un nuevo derecho público. Estudios de derecho público comparado, supranacional e internacional, UNAM-IIJ, México, 2011, pp. 423-444.

23 Carbonell, "Derecho a migrar", op. cit., p. 63.

24 "La llamada teoría de los procesos jurídicos transnacionales intenta captar, describir y explicar estos procesos dinámicos de creación, interpretación y aplicación de normas jurídicas internacionales por parte de actores tan diversos como gobiernos nacionales, organizaciones internacionales, empresas multinacionales, organizaciones no gubernamentales, redes de peritos profesionales y hasta individuos". Gomes Canotilho, José Joaquim, "Principios y 'nuevos constitucionalismos': el problema de los nuevos principios", Revista de Derecho Constitucional Europeo, 2010, 7, (14), pp. 321-364, especialmente p. 327. 
entre los distintos órdenes jurídicos: estatales, internacionales, transnacionales, supranacionales y locales". ${ }^{25}$

El proceso de gestación de un constitucionalismo global, en el sentido de traspasar las fronteras, se proyecta sobre todo a la labor que desarrolla el juez. Así:

algunos de los integrantes de un número importante de tribunales constitucionales han considerado al derecho comparado como una herramienta útil en sus procesos interpretativos y han comenzado a interactuar con otros órganos de control, tomando como referencia los casos resueltos en otros países y ofreciendo sus propios razonamientos para participar en un proceso de diálogo entre jueces constitucionales. Este proceso dialógico ha cobrado mayor fuerza debido a que los problemas comunes y las necesidades globales que enfrentan los Estados han hecho crecer la necesidad de conocer no sólo las reglas escritas o la doctrina que se crea en el mundo académico, sino también las reglas operacionales, los modelos de sentencia y las técnicas de razonamiento que, en el ámbito jurisdiccional, ofrecen las experiencias extranjeras. ${ }^{26}$

En esta línea, Claire L'Heureux-Dubé razona sobre la base de que la globalización también está ocurriendo en los procesos de juzgamiento y abogacía, y que los vínculos e influencias internacionales están afectando y cambiando las decisiones judiciales, particularmente al nivel de las más altas cortes en el mundo. ${ }^{27}$

Desde el punto de vista jurisprudencial, el Tribunal Constitucional chileno, en el conocido caso de Rodrigo Ubilla Mackenney, relativo a los correos electrónicos y a propósito de la invocación o utilización en el razonamiento judicial de normas constitucionales vigentes en otros países,

25 Neves, Marcelo, Transconstitucionalismo, $1^{\mathrm{a}}$ ed., WMF: Martins Fontes, São Paulo, 2009, p. 100.

26 Brito Melgarejo, Rodrigo, "El uso de sentencias extranjeras en los tribunales constitucionales. Un análisis comparativo", InDret Revista para el Análisis del Derecho, 2002, (2), pp. 1-22, especialmente p. 6.

27 L'Heureux-Dubé, Claire, "The Importance of dialogue: globalization and the international impact of the rehnquist court", Tulsa Law Journal, 1998, 34, (1), pp. 15-40, especialmente p. 16. 
ha reconocido la existencia de un constitucionalismo global asimilándolo a un derecho constitucional común. ${ }^{28}$

El Tribunal Constitucional se apoya en dos grandes autores de nuestro tiempo para efectuar esta afirmación, o, más bien, constatación. Se trata de los profesores Luigi Ferrajoli y Peter Häberle, dos grandes figuras del Viejo Continente que, sin duda, han marcado la pauta en esta línea de pensamiento. ${ }^{29}$ A partir de este pronunciamiento del Tribunal Constitucional chileno, la pregunta que resta por formularse es, si estas manifestaciones de constitucionalismo global han estimulado, al menos, un emergente ius commune interamericanum.

\section{E1 nuevo 'ius commune interamericanum'}

Es comúnmente aceptado que en el siglo XXI el Estado no es más el exclusivo detentor del poder creador de normas. La creación ya no es una cuestión de exclusividad en la esfera estatal. Jacques Chevallier ha mencionado que "la mundialización no podría dejar de tener incidencia en el derecho: abriendo una brecha en el monopolio que los Estados-nación se habían arrogado sobre el derecho; la mundialización destruye los fundamentos del derecho moderno, tal como ellos habían sido planteados en el pensamiento occidental entre el siglo XVI y el siglo XVIII". ${ }^{30} \mathrm{Y}$ tampoco es así en el ámbito internacional. En este último sentido, Mireille DelmasMarty ha sostenido que, "si los Estados permanecen en el corazón de los

\footnotetext{
28 "No obstante, hay, sin duda, un derecho constitucional común o un 'constitucionalismo global'. Hay normas que son universales, que tienen autoridad moral. Sin embargo, esta magistratura no puede utilizar el derecho constitucional extranjero como parámetro para resolver un asunto sometido a su conocimiento. Como recién señalamos, sólo puede servir para ilustrar, proporcionar argumentos y transmitir experiencias, además de establecer comparaciones". Tribunal Constitucional de Chile, Requerimiento de inaplicabilidad por inconstitucionalidad presentado por Rodrigo Ubilla Mackenney, subsecretario del Interior, respecto del inciso segundo, del artículo $5^{\circ}$ de la Ley 20.285, de 2008, sobre acceso a la información pública, en los autos sobre reclamo de ilegalidad caratulados "Subsecretaría Interior con Consejo para la Transparencia", de que conoce la Corte de Apelaciones de Santiago, bajo el Rol No 6704-2011, Rol No 2153-11, sentencia de fecha 11 de septiembre de 2012, considerando $8^{\circ}$.

29 Ferrajoli, Luigi, "Más allá de la soberanía y de la ciudadanía: un constitucionalismo global", Isonomía, 1998, (9), p. 173 y ss.; Häberle, Peter, "Derecho constitucional común europeo", Revista de Estudios Políticos, 1993, (79), pp. 7 y ss.

30 Chevallier, Jacques, «Mondialisation du droit ou droit de la mondialisation», en Morand, Charles-Albert (Dir.), Le droit saisi par la mondialisation, Bruylant, Bruxelles, 2001, pp. 37-61.
} 
dispositivos internacionales de producción normativa, ellos no tienen más el monopolio". 31

El derecho tiende a ser un derecho material que se va construyendo en lugar de ser dictado, donde intervienen agentes estatales y ciudadanos, en cambio de solo poderes del Estado. El derecho, en esta etapa, más que puro enunciado lingüístico, se complementa con principios cuya aplicación requiere una sólida explicación y justificación razonada para ser aceptado, y con valores morales que exigen una concreción práctica a través de la argumentación, que les da una justificación y una razón social. En este sentido, Chevallier ha señalado que la "mundialización no solamente afectaría las formas y las modalidades de la regulación jurídica, sino también ella obligaría a repensar el derecho". 32

El derecho de origen estatal, especialmente el derecho constitucional y el derecho internacional, ha seguido en determinados aspectos desde la Segunda Guerra Mundial, procesos similares. ${ }^{33}$ Nos referimos al lugar preeminente que han pasado a ocupar los derechos humanos, tanto en una como en otra área, y en general, a la transición desde un derecho formal, basado en distribución y asignación de competencias, a un derecho basado en valores fundamentales. Una expresión de estos valores fundamentales, tanto para el derecho constitucional como para el derecho internacional, son los derechos humanos y el gran potencial que ellos implican para el individuo y los pueblos. En este sentido, Tomuschat ha sugerido que la sociedad — en nuestra opinión tanto estatal como internacional— se está "desplazando progresivamente desde un sistema centrado en la soberanía a uno orientado a los valores o a los individuos". 34 También se ha señalado que ciertos tratados internacionales importantes — podrían ser los tratados de derechos humanos - constituyen un derecho internacional que cumple una función complementaria del derecho constitucional interno. ${ }^{35}$

31 Delmas-Marty, Mireille, «Les processus de mondialisation du droit», en Morand, Charles-Albert (Dir.), Le droit saisi par la mondialisation, Bruylant, Bruxelles, 2001, pp. 63-80.

32 Chevallier, «Mondialisation du droit...», op. cit., p. 38.

33 Dulitzky, Ariel, "Los tratados de derechos humanos en el constitucionalismo iberoamericano", en Buergenthal, Thomas \& Cançado Trindade, A. A. (Comps.), Estudios especializados de derechos bumanos, tomo I, Instituto Interamericano de Derechos Humanos, San José, 1996, pp. 129-166.

34 Tomuschat, "International law...”, op. cit., p. 237.

35 Ver Von Bogdandy, Armin, "Constitutionalism in international law: comment on a proposal from Germany”, Harvard International Law Journal, 2006, 47, (1), pp. 223-242, 
En definitiva, a la luz de lo que se ha indicado, se podría argumentar que la consecuencia propia del derecho internacional de los derechos humanos ha sido la gestación de un nuevo ius commune o que los derechos humanos se configurarían como el nuevo derecho común del mundo contemporáneo.

Este ius commune ha sido definido muy bien por el profesor Jorge Carpizo, quien ha señalado lo siguiente:

la Convención Americana y su interpretación de última instancia, realizada por la Corte Interamericana de Derechos Humanos (Corte IDH), está creando un ius commune latinoamericano de derechos humanos, que implica que cualquier habitante de la región goza de un mínimo de derechos que la Constitución de cada país puede ampliar, pero nunca restringir, en virtud de las obligaciones internacionales que cada Estado contrajo al ratificar la propia Convención Americana y aceptar la jurisdicción obligatoria de la Corte IDH. ${ }^{36}$

Por su parte, José María Serna de la Garza ha sostenido, definiendo el ius commune, que:

[e]n primer lugar, podemos mencionar que los países del sistema interamericano de derechos humanos comparten en sus constituciones una serie de valores comunes, centrados en la dignidad de la persona humana y los derechos que de ella irradian. En segundo lugar, existe un bloque normativo común a los Estados adscritos al sistema interamericano de protección de los derechos humanos: la Convención Americana de Derechos Humanos y la jurisprudencia de la Corte Interamericana de Derechos Humanos. ${ }^{37}$

especialmente p. 226; Uerpmann, Robert, “The constitutional role of multilateral treatises", en Von Bogdandy, Armin \& Bast, Jorgen (Eds.), Principles of European constitutional law, Hart Publishing, Oxford, 2006.

36 Von Bogdandy, Armin, "Ius constitutionale commune latinoamericanum. Una aclaración conceptual desde una perspectiva europea”, en González Pérez, Luis Raúl \& Valadés, Diego (Coords.), El constitucionalismo contemporáneo. Homenaje a Jorge Carpizo, UNAM-II, México, 2013, pp. 39-66, especialmente p. 43.

37 Serna de la Garza, José María, "Jorge Carpizo y el proyecto 'Hacia un ius commune latinoamericano en derechos humanos”, en González Pérez y Valadés, El constitucionalismo contemporáneo..., op. cit., pp. 35-38, especialmente p. 36. 
Desde este punto de vista, nos gustaría traer a colación lo que el profesor Héctor Gros Spiell señaló en varias ocasiones en el sentido de que todos los derechos humanos son derechos fundamentales, afirmación que muestra la inadecuación de una visión separadora de la realidad constitucional con la realidad internacional. ${ }^{38}$ Ingo Sarlet, en cambio, indica algunas de las dificultades que podría enfrentar este derecho común interamericano, cuando señala que "sin el fortalecimiento de las bases de la ciudadanía (o sea, sin la garantía de una titularidad universal en la esfera del 'status activus processualis', tan querido por nuestro homenajeado), a través de la superación también de la inestabilidad político-institucional que se manifiesta en buena parte del territorio latinoamericano, un derecho constitucional común tendrá dificultades de fructificar en toda su deseable extensión". ${ }^{39}$ Por cierto que fortalecer la ciudadanía y superar la inestabilidad político-institucional en Latinoamérica es evidentemente la base para desarrollar el ius commune. En este sentido, ya hemos mencionado que los pilares básicos de carácter constitucional de un sistema de derecho como este son los derechos humanos, el Estado de derecho y la democracia. No es posible construir nada que se estime constitucional si no es a partir de estos tres elementos básicos.

Hay autores que hablan a secas de un ius constitutionale commune, sin realizar en principio, una localización geográfica específica. ${ }^{40}$ Luego, la doctrina efectúa algunas concretizaciones espaciales, y utilizando en este sentido distintas denominaciones, aun cuando es posible desprender que de una u otra forma todas se refieren al ámbito espacial cubierto por los Estados que se han sometido a la jurisdicción de la Corte IDH. A partir de esta idea, una primera pista acerca de este ius commune tiende a identificarlo con la actividad jurisdiccional de este tribunal internacional. Como se puede

38 Gros Espiell, Héctor, "La dignidad humana en los instrumentos internacionales sobre derechos humanos", Anuario de Derechos Humanos, 2003, 4, pp. 193-223, especialmente p. 202; Gros Espiell, Héctor, "Una mirada actual a la Declaración Universal de los Derechos Humanos", Estudios, 2009, VII, (91), pp. 69-87.

39 Sarlet, Ingo, "Posibilidades y desafíos de un derecho constitucional común latinoamericano. Un planteamiento a la luz del ejemplo de la llamada prohibición de retroceso social", Revista de Derecho Constitucional Europeo, 2009, 6, (11), pp. 87-134, especialmente p. 133.

40 Morales Antoniazzi, Mariela, "El Estado abierto como objetivo del ius constitutionale commune. Aproximación desde el impacto de la Corte Interamericana de Derechos Humanos", en Von Bogdandy, Fix-Fierro \& Morales Antoniazzi, Ius constitutionale..., op. cit., pp. 265-299. 
ver, esta es una primera pieza que arroja luces en el entendimiento de este ius commune, pero no es solo esta actividad jurisdiccional, ni mucho menos este derecho común se agota en esta actividad. Como se verá, parece ser que el ius commune del que estamos hablando se refiere a verdaderos elementos fundantes — de una comunidad política democrática— de carácter constitucional. De este modo, desde el punto de vista espacial, también ha habido autores como Von Bogdandy que se han centrado en la denominación ius constitutionale commune latinoamericanum, aun cuando ha aclarado que entiende este término como sinónimo del ius commune o derecho común. ${ }^{41}$ Otro sector de la doctrina se refiere a un ius commune latinoamericanum. ${ }^{42}$ Igualmente, existen autores que han aludido a un ius constitutionale commune americanum, ${ }^{43}$ o bien, más ampliamente, a un ius commune americanum. ${ }^{44}$ Por último, otros como Gilmar Ferreira usan derecho constitucional común iberoamericano. ${ }^{45}$ Este fenómeno incluso se ha extendido a otros ámbitos del derecho público, tales como el derecho administrativo, y es así como se alude al derecho administrativo común interamericano. ${ }^{46}$ Incluso, desde un

41 Von Bogdandy, “Ius constitutionale...”, op. cit.; Sarlet, "Posibilidades y desafíos...”, op. cit.

42 Serna de la Garza, José María, "El concepto de ius commune latinoamericano en derechos humanos: elementos para una agenda de investigación", en Von Bogdandy, Fix-Fierro \& Morales Antoniazzi, Ius constitutionale..., op. cit., pp. 199-217.

43 Gómez Gamboa, David Augusto, "Hacia un ius constitutionale commune americanum", Frónesis, 2013, 20, (3), pp. 447-466; Corte IDH, Supervisión de cumplimiento de sentencia en el caso Gelman vs. Uruguay, resolución de la Corte Interamericana de Derechos Humanos del 20 de marzo de 2013, voto razonado del juez Eduardo Ferrer Mac-Gregor Poisot a la resolución de la Corte Interamericana de Derechos Humanos del 20 de marzo de 2013, para. 100.

44 Häberle, Peter, "México y los contornos de un derecho constitucional común americano o ius commune americanum", en Häberle, Peter \& Kotzur, Markus, De la soberanía al derecho constitucional común: palabras clave para un diálogo europeo latinoamericano, traducción de Héctor Fix-Fierro, $1^{a}$ reimpresión, UNAM-IIJ, México, 2011, pp. 1-83.

45 Ferreira Mendes, Gilmar, "La doctrina de un derecho común iberoamericano: consideraciones en homenaje a la doctrina de Peter Häberle y su influencia en Brasil", Revista de Derecho Constitucional Europeo, 2009, 6, (11), pp. 65-86.

46 Jinesta, Ernesto, "La construcción de un derecho administrativo común interamericano: reformulación de las fuentes del derecho administrativo con la constitucionalización del derecho internacional de los derechos humanos", Revista Iberoamericana de Derecho Público y Administrativo, 2011, 11, (11), pp. 1-16. 
punto de vista del derecho de la integración y bajo la influencia del derecho comunitario, Juan Pablo Pampillo se refiere a un ius commune americano. ${ }^{47}$

Nosotros usaremos en este trabajo, en general, el término ius constitutionale commune o derecho constitucional común o derecho común como indistintos. Y entenderemos que todas las denominaciones geográficas quedan comprendidas en el término 'interamericano'. Específicamente, proponemos el uso de la expresión interamericanum porque este ius commune surge primordialmente de la actividad que desempeñan los órganos interamericanos de protección de los derechos humanos. Además, porque este ius commune surge de los instrumentos interamericanos de protección de los derechos humanos y, por esta razón, la doctrina alude a un corpus iuris interamericano. ${ }^{48}$ Con todo, para nuestros efectos, debe señalarse que interamericanum incluye solo a los Estados que han aceptado la jurisdicción de la Corte IDH, lo que significa Estados como Perú, Brasil y Haití.

¿Cuál sería el concepto de ius constitutionale commune? ¿Cuáles serían los conceptos claves de un ius constitutionale commune? El ius constitutionale commune se referiría a los pilares de carácter constitucional que debería poseer y respetar toda comunidad humana para fundar el pacto social básico. Estos pilares estarían constituidos por la democracia, los derechos humanos y el Estado de derecho.

¿Cuáles serían los rasgos esenciales de un ius constitutionale commune interamericanum? El ius constitutionale commune interamericanum hace referencia

47 Pampillo Baliño, Juan Pablo, "Derecho comunitario y ius commune americano: dos asignaturas pendientes para las ciencias jurídicas de nuestro continente", Foro, Revista de Derecho, 2012, (18), pp. 5-29.

48 Nogueira Alcalá, Humberto, "Los desafíos del control de convencionalidad del corpus iuris interamericano para los tribunales nacionales y su diferenciación con el control de constitucionalidad", en Nogueira Alcalá, Humberto, Derechos fundamentales, bloque constitucional de derechos, diálogo interjurisdiccional y control de convencionalidad, Ubijus Editorial, México, 2014, pp. 585-641. "Como se ha dicho anteriormente, los Estados tienen la obligación de reconocer y respetar los derechos y libertades de la persona humana, así como proteger y asegurar su ejercicio a través de las respectivas garantías (artículo 1.1), medios idóneos para que aquéllos sean efectivos en toda circunstancia, tanto el corpus iuris de derechos y libertades como las garantías de éstos, son conceptos inseparables del sistema de valores y principios característico de la sociedad democrática. En esta 'los derechos y libertades inherentes a la persona, sus garantías y el Estado de derecho constituyen una tríada, cada uno de cuyos componentes se define, completa y adquiere sentido en función de los otros". Corte IDH, Opinión Consultiva OC-17/2002 del 28 de agosto de 2002, solicitada por la Comisión Interamericana de Derechos Humanos sobre la condición jurídica y derechos bumanos del niño, para. 92. 
a un derecho común en América que se construiría a partir de un entendimiento armonioso y convergente de los derechos humanos en el sistema interamericano, liderado por la Corte IDH. ¿Cuál sería la articulación entre ius constitutionale commune y el diálogo entre jueces en derechos humanos? En este sentido, Bárbara Cardoso destaca una idea clave de la nueva perspectiva de análisis de la interacción entre el plano interno e internacional, refiriéndose a la aproximación entre las cortes en la forma de diálogo, en un contexto de pluralismo jurídico. ${ }^{49}$ André de Carvalho Ramos resalta que sería a través del diálogo entre las cortes y una fertilización cruzada entre derecho interno y derecho internacional, lo que resolvería un eventual conflicto aparente de normas. ${ }^{50}$ Antonio Cançado apunta a un criterio más sustancial de solución, afirmando que lo que debe prevalecer es la norma más favorable para las víctimas, la que mejor las proteja, sea la norma interna o la norma internacional. ${ }^{51}$ ¿Cuáles serían los objetivos de un ius constitutionale commune? Lograr un nivel mínimo de protección y garantía de los derechos de los individuos en las comunidades estatales, a partir de una idea global del estándar mínimo de derechos, para cuya determinación la regla de oro sería el principio pro homine. De esta manera, este entendimiento común se gestaría fundamentalmente a través del diálogo entre jueces de distintos niveles jurisdiccionales y en función de ciertos principios operacionales, tales como el principio pro bomine. ${ }^{52}$ Resta por ver si una de las vías posible por medio de las cuales se concreta este diálogo jurisdiccional internacional podría ser el control de convencionalidad. En este sentido, podría adelantarse — como veremos a continuación- que el control de convencionalidad, con los instrumentos interamericanos de

49 Cardoso Campos, Bárbara Pincowsca, "Controle de convencionalidade: aproximação entre o direito internacional é o constitucionalismo?", Revista do Instituto Brasileiro de Direitos Humanos, 2013, 13, (13), pp. 47-58, especialmente p. 53.

50 Ramos, André de Carvalho, Processo internacional de direitos bumanos, $2^{\mathrm{a}}$ ed., Saraiva, Sao Paulo, 2012, p. 375.

51 Cançado Trindade, Antonio Augusto, Tratado de direito internacional dos direitos bumanos, vol. I, Editor Fabris, Porto Alegre, 1997, p. 444.

52 Salvioli, Fabián, "Un análisis desde el principio pro persona sobre el valor jurídico de las decisiones de la Comisión Interamericana de Derechos Humanos", en En defensa de la Constitución: un homenaje a Germán Bidart Campos, Ediar, Buenos Aires, 2003, pp. 143-155; Amaya Villarreal, Álvaro Francisco, "El principio pro homine: interpretación extensiva vs. el consentimiento del Estado", International Law: Revista Colombiana de Derechos Internacional, 2005, (5), pp. 337-380. 
derechos humanos y la jurisprudencia de la Corte IDH, habría potenciado la emergencia de un ius commune interamericanum en derechos humanos.

\section{E1 control de convencionalidad según la Corte Interamericana de Derechos Humanos}

En Latinoamérica, el control de convencionalidad es, antes que todo, una doctrina de carácter pretoriana. La noción de control de convencionalidad tuvo su origen en los votos separados del juez Sergio García Ramírez y posteriormente adquirió 'carta de nacionalidad' con su incorporación a las sentencias de la Corte IDH. ${ }^{53}$ Con todo, la noción y la técnica de este control tienen, claramente, una inspiración en la teoría constitucional

53 "En este orden, la responsabilidad es global, atañe al Estado en su conjunto y no puede quedar sujeta a la división de atribuciones que señale el derecho interno. No es posible seccionar internacionalmente al Estado, obligar ante la Corte sólo a uno o algunos de sus órganos, entregar a estos la representación del Estado en el juicio — sin que esa representación repercuta sobre el Estado en su conjunto- y sustraer a otros de este régimen convencional de responsabilidad, dejando sus actuaciones fuera del 'control de convencionalidad' que trae consigo la jurisdicción de la Corte Internacional”. Corte IDH, Caso Myrna Mack. Chang vs. Guatemala, sentencia del 25 de noviembre de 2003, (fondo, reparaciones y costas), voto concurrente razonado del juez Sergio García Ramírez, considerando 27. "En cierto sentido, la tarea de la Corte se asemeja a la que realizan los tribunales constitucionales. Estos examinan los actos impugnados — disposiciones de alcance general — a la luz de las normas, los principios y los valores de las leyes fundamentales. La Corte Interamericana, por su parte, analiza los actos que llegan a su conocimiento en relación con normas, principios y valores de los tratados en los que funda su competencia contenciosa. Dicho de otra manera, si los tribunales constitucionales controlan la 'constitucionalidad', el tribunal internacional de derechos humanos resuelve acerca de la 'convencionalidad' de esos actos. A través del control de constitucionalidad, los órganos internos procuran conformar la actividad del poder público —y eventualmente, de otros agentes sociales — al orden que entraña el Estado de derecho en una sociedad democrática. El tribunal interamericano, por su parte, pretende conformar esa actividad al orden internacional acogido en la convención fundadora de la jurisdicción interamericana y aceptado por los Estados partes en ejercicio de su soberanía". Corte IDH, Caso Tibi vs. Ecuador, sentencia del 7 de septiembre de 2004, (excepciones preliminares, fondo, reparaciones y costas), voto concurrente razonado del juez Sergio García Ramírez, considerando 3; Corte IDH, Caso Almonacid Arellano y otros vs. Chile, (excepciones preliminares, fondo, reparaciones y costas), sentencia del 26 de septiembre de 2006, Serie C No 154; Corte IDH, Caso Trabajadores Cesados del Congreso (Aguado Alfaro y otros) vs. Perú, (excepciones preliminares, fondo, reparaciones y costas), sentencia del 24 de noviembre de 2006, Serie C No 158; Corte IDH, Caso Radilla Pacheco vs. México, (excepciones preliminares, fondo, reparaciones y costas), sentencia del 23 de noviembre de 2009, Serie C No 209; Corte IDH, Caso Cabrera García y Montiel Flores vs. México, (excepción 
francesa. ${ }^{54}$ Además, se ha sostenido que el control de convencionalidad le pone nombre a una actividad que la Corte IDH ya venía realizando desde el comienzo de su funcionamiento y que los Estados partes en la Convención Americana sobre Derechos Humanos (en adelante, la CADH) y sujetos a la jurisdicción de la Corte IDH, a través de sus órganos internos, tienen el deber de ejecutar en cumplimiento de sus obligaciones internacionales. ${ }^{55}$

En este sentido, Cardoso ha sostenido que "el control de convencionalidad es, en líneas generales, un proceso de verificación de la (in) compatibilidad de los actos internos y normas jurídicas de un Estado en relación a los tratados internacionales de los cuales es parte". ${ }^{56}$

El amplio interés y desarrollo doctrinario que ha generado en la última década el control de convencionalidad en el sistema interamericano de protección de los derechos humanos ha provocado el surgimiento de múltiples clasificaciones, que no son del caso explicar en este trabajo. Así, se ha mencionado el control internacional y nacional de convencionalidad. ${ }^{57}$ También, el control interno y externo de convencionalidad. ${ }^{58}$ Por otra parte, el falso y verdadero control de convencionalidad. ${ }^{59} \mathrm{El}$ control difuso y concentrado de convencionalidad. ${ }^{60}$ Así mismo, el control débil

preliminar, fondo, reparaciones y costas), sentencia del 26 de noviembre de 2010, Serie C $\mathrm{N}^{\circ} 220$.

54 Dutheillet de Lamothe, Olivier, «Contrôle de conventionnalité et contrôle de constitutionnalité en France», en http://www.conseil-constitutionnel.fr/conseil-constitutionnel/root/bank_mm/pdf/Conseil/madrid_odutheillet_avril_2009.pdf, consulta del 12 de diciembre de 2014; Dutheillet de Lamothe, Olivier, "Contrôle de constitutionnalité et contrôle de conventionnalité», en Mélanges en l'honneur de Daniel Labetoulle, Dalloz, Paris, 2007.

55 Castilla Juárez, Karlos A., "Control de convencionalidad interamericano: una mera aplicación del derecho internacional”, Derecho del Estado, 2014, (33), pp. 149-172, especialmente p. 161.

56 Cardoso Campos, “Controle de convencionalidade...”, op. cit., p. 49.

57 Nash Rojas, Claudio, "El control de convencionalidad: incógnitas, desafíos y perspectivas", en Bazán, Víctor \& Nash, Claudio (Eds.), Justicia constitucionaly derechos fundamentales. El control de convencionalidad, Konrad Adenauer Stiftung E.V., Bogotá, 2012, pp. 57-70.

58 García Ramírez, Sergio, "El control judicial interno de convencionalidad”, IUS, Revista del Instituto de Ciencias Jurídicas de Puebla, 2011, V, (28), pp. 123-159.

59 Castilla Juárez, "Control de convencionalidad...”, op. cit.

${ }^{60}$ Ferrer Mac-Gregor, Eduardo, "Interpretación conforme y control difuso de convencionalidad. El nuevo paradigma para el juez mexicano", Estudios Constitucionales, 2011, 9, (2), pp. 531-622. 
y fuerte de convencionalidad. ${ }^{61} \mathrm{Y}$, junto con los anteriores, el control primario y el control complementario de convencionalidad. ${ }^{62}$

El control de convencionalidad consiste, en sus aspectos básicos, en la obligación que tendrían los Estados partes en la Convención Americana sobre Derechos Humanos, a través de todos sus órganos y especialmente sus jueces, de velar por el respeto y cumplimiento de las obligaciones convencionales que el Estado habría contraído y asumido al ratificar la CADH, tenien do especialmente presente su preámbulo, las obligaciones generales que emanan de sus artículos $1^{\circ}$ y $2^{\circ}$, el carácter de la Corte Interamericana de Derechos Humanos (Corte IDH) de intérprete auténtico y final de la Convención, determinado por su artículo 62, como en el caso particular de Chile, de la expresión de voluntad del Estado de Chile en el Decreto Promulgatorio de la Convención Americana sobre Derechos Humanos No 873 de Relaciones Exteriores del 23 de agosto de 1990, letra b), que sostiene: "El gobierno de Chile declara que reconoce como obligatoria de pleno derecho la competencia de la Corte Interamericana de Derechos Humanos respecto de los casos relativos a la interpretación y aplicación de esta Convención de conformidad con lo que dispone su artículo 62".

Completa este concepto las reglas de interpretación de los derechos del artículo 29 de la CADH, así como las competencias de la Corte IDH para emitir opiniones consultivas (art. 64) y sentencias conforme a los artículos 67, 68 y 69 de la CADH, las cuales son irrecurribles, constituyen cosa juzgada y obligación de resultado para los Estados partes. Ello se vería reforzado, según determina la propia Corte IDH, en virtud de los principios imperativos de derecho internacional contenidos en la Convención de Viena sobre Derecho de los Tratados de 1969, especialmente sus artículos 26, 31.1 y 27, los cuales determinan el deber de cumplir de buena fe las obligaciones internacionales y no oponen obstáculos de derecho interno al cumplimiento de ellas, posición que ha sido asumida por los órganos jurisdiccionales chilenos.

${ }^{61}$ Contreras, Pablo, "Control de convencionalidad fuerte y débil: parte I", Diario Constitucional, 17 de agosto de 2012, en http://diarioconstitucional.cl/articulos/controlde-convencionalidad-fuerte-y-debil-parte-i/, consulta del 12 de diciembre de 2014.

62 Gómez Gamboa, "Hacia un ius constitutionale...”, op. cit. 
El inicio de este enfoque jurisdiccional y convencional por parte de la Corte IDH se encuentra en la sentencia del caso Almonacid Arellano y otros vs. Chile, adoptada por unanimidad. ${ }^{63}$

Además, se debe mencionar la sentencia reciente en el caso chileno denominado Atala Riffo y niñas vs. Chile, en la medida que la Corte IDH ratifica y consolida para el caso chileno la doctrina del control de convencionalidad difuso, incluyendo la judicatura y la administración, en el seguimiento de la interpretación emanada de la jurisprudencia de la referida Corte, en aplicación del control de convencionalidad:

En conclusión, con base en el control de convencionalidad, es necesario que las interpretaciones judiciales y administrativas y las garantías judiciales se apliquen adecuándose a los principios establecidos en la jurisprudencia de este tribunal en el presente caso. Ello es de particular relevancia en relación con lo señalado en el presente caso respecto a la proscripción de la discriminación por la orientación sexual de la persona de acuerdo a lo estipulado en el artículo 1.1 de la Convención Americana. ${ }^{64}$

A partir de las enseñanzas del juez Sergio García Ramírez —en los casos Myrna Mack Chang y Tibi-y, posteriormente, de la Corte IDH —en el caso Almonacid Arellano y otros-, Cardoso ha sostenido que

63 "La Corte es consciente que los jueces y tribunales internos están sujetos al imperio de la ley y, por ello, están obligados a aplicar las disposiciones vigentes en el ordenamiento jurídico. Pero cuando un Estado ha ratificado un tratado internacional como la Convención Americana, sus jueces, como parte del aparato del Estado, también están sometidos a ella, lo que les obliga a velar porque los efectos de las disposiciones de la Convención no se vean mermados por la aplicación de leyes contrarias a su objeto y fin, y que desde un inicio carecen de efectos jurídicos. En otras palabras, el poder judicial debe ejercer una especie de 'control de convencionalidad' entre las normas jurídicas internas que aplican en los casos concretos y la Convención Americana sobre Derechos Humanos. En esta tarea, el poder judicial debe tener en cuenta no solamente el tratado, sino también la interpretación que del mismo ha hecho la Corte Interamericana, intérprete última de la Convención Americana". Corte IDH, Caso Almonacid Arellano y otros vs. Chile, sentencia del 26 de septiembre de 2006, (excepciones preliminares, fondo, reparaciones y costas), para. 124.

64 Corte IDH, Caso Atala Riffo y Niñas vs. Chile, sentencia del 24 de febrero de 2012, (fondo, reparaciones y costas), para. 284. 
los magistrados y tribunales domésticos, además de aplicar las normas previstas en el ordenamiento interno, deben garantizar la aplicación y la implementación de las obligaciones convencionales asumidas por el Estado. [...] Es importante aclarar que la propia Corte Interamericana realiza también — y en todo tiempo- un control jurisdiccional directo al examinar la adecuación de las normas internas de los Estados parte, en casos concretos, con la Convención Americana [...]. ${ }^{65}$

En resumen, de acuerdo con esta perspectiva, puede señalarse que, en sus aspectos centrales, el control de convencionalidad difuso implica las siguientes características: primero, todos los órganos del Estado parte, incluidos los jueces de todos los niveles, están obligados a velar por que los efectos de la Convención no se vean afectados por la aplicación de normas jurídicas internas contrarias a su objeto y fin, concretando un control de convencionalidad de estas últimas. Segundo, este control de convencionalidad debe ser efectuado por los órganos internos y los jueces de todo nivel ex officio, otorgándole un efecto útil y efectivo a la Convención Americana de Derechos Humanos. Tercero, en dicho control de convencionalidad debe considerarse no solo el tratado, sino la interpretación que de este realiza la Corte IDH como intérprete auténtico y final. Cuarto, los órganos internos, incluidos los jueces, deben efectuar dicho control dentro de sus respectivas competencias y de las regulaciones procesales vigentes. Quinto, en el control de convencionalidad no se aplica solo la Convención Americana sobre Derechos Humanos, sino el corpus iuris vinculante para el Estado parte en virtud del artículo 29 de la CADH. Y, sexto, dicho control de convencionalidad debe hacerse adecuándose a los principios establecidos por la Convención y las garantías judiciales que operan en la materia.

Por otra parte, un elemento que merece ser resaltado es que la sentencia condenatoria en el caso Almonacid Arellano y otros fue en parte cumplida por el Estado de Chile. En particular, cabe mencionar que los tribunales chilenos, a quienes iba dirigido fundamentalmente el fallo de la Corte IDH, reabrieron el caso, investigaron, juzgaron y sancionaron a los responsables de las violaciones a los derechos humanos. ${ }^{66}$

\footnotetext{
65 Cardoso Campos, “Controle de convencionalidade...”, op. cit., p. 50.

66 Ver Corte de Apelaciones de Rancagua, Homicidio simple de Luis Almonacid Arellano, recurso de apelación, Rol No 103-2011, sentencia de fecha 14 de enero de 2013; "La Corte Suprema dictó sentencia en la investigación por el homicidio calificado de Luis Almonacid Arellano, ocurrido el 16 de septiembre de 1973, en la ciudad de Rancagua, caso que volvió a
} 
Esta figura se acerca bastante a aquella ya establecida en el derecho europeo y relacionado con el principio de primacía de dicho derecho (antes llamado derecho comunitario). En efecto, en el seno de lo que hoy se entiende por derecho europeo, una serie de decisiones jurisprudenciales de la década de los setenta cimentó el terreno para que el juez ordinario nacional decidiera, por sí mismo e inmediatamente, sobre una ley interna contraria al derecho europeo (comunitario). ${ }^{67}$ La sentencia del 9 de marzo de 1978 del actual Tribunal de Justicia de la Unión Europea (TJUE), en el conocido caso Simmenthal, sentó las bases para el principio del efecto directo y la primacía del derecho europeo (comunitario). ${ }^{68}$

Como consecuencia de esta jurisprudencia, Germán Teruel ha señalado que "el juez nacional deberá dejar sin aplicación todas aquellas normas internas que, aun temporalmente, se opusieran a una disposición comunitaria y pudieran obstaculizar su plena eficacia". ${ }^{69}$

Lo que pretendemos en este artículo es determinar si el control de convencionalidad es una manifestación del ius constitutionale commune basado en los derechos humanos en el ámbito interamericano.

Esta idea se sustenta sobre la base de que, desde el siglo xx, los derechos humanos han articulado un cuerpo de normas básicas, un corpus iuris, comúnmente aceptadas por la comunidad internacional. En este

investigarse por la justicia civil luego de que la Corte Interamericana de Derechos Humanos resolviera dejar sin efecto el proceso cerrado en la justicia militar por la aplicación del D.L. 2.191, Ley de Amnistía". Ver Corte Suprema de Chile, Homicidio calificado de Luis Almonacid Arellano, recurso de casación en el fondo, Rol No $1260-13$, sentencia de fecha 29 de julio de 2013, en http://www.pjud.cl/, consulta del 3 de diciembre de 2014.

67 Desde una perspectiva crítica, comentando el caso Costa/Enel de 1964 ante el TJCE, ver Hillgruber, Christian, "La integración del derecho internacional y del derecho de la Unión Europea en el ordenamiento constitucional alemán”, Revista de Derecho Constitucional Europeo, 2004, (1), pp. 115-138, especialmente p. 118.

68 "Que el juez nacional encargado de aplicar, en el marco de su competencia, las disposiciones del derecho comunitario, está obligado a garantizar la plena eficacia de dichas normas dejando, si procede, inaplicadas, por su propia iniciativa, cualesquiera disposiciones contrarias de la legislación nacional, aunque sean posteriores, sin que esté obligado a solicitar o a esperar la derogación previa de éstas por vía legislativa o por cualquier otro procedimiento constitucional". TJCE, Amministrazione delle Finanze dello Stato y SpA Simmenthal, sentencia del Tribunal de Justicia del 9 de marzo de 1978, asunto 106/77, para. 24.

69 Teruel Lozano, Germán M., "El Tribunal Constitucional ante el principio de primacía del derecho comunitario (análisis de la jurisprudencia constitucional respecto de la compatibilidad del principio de primacía con la Constitución de la nación española de 1978)", Anales de Derecho, Universidad de Murcia, 2006, (24), pp. 319-352, especialmente p. 331. 
sentido, las jurisdicciones internacionales de derechos humanos han jugado un rol fundamental en generar, a través de su interpretación, un entendimiento básico común de los derechos humanos. Así ha ocurrido con la Corte Europea de Derechos Humanos (Corte EDH) y así ha ocurrido con la Corte Interamericana de Derechos Humanos. En nuestra opinión, teóricamente, esta tarea ha sido más sencilla para la Corte IDH que para la Corte EDH, ya que, en el caso de la Corte IDH, los Estados partes y que han aceptado su jurisdicción, en general, comparten elementos y visiones materiales y espirituales comunes, tienen una religión común, hablan la misma lengua, provienen de un mismo colonizador, han tenido experiencias humanas similares, etc. (salvo los países de América del Norte y algunos países del Caribe). Estos factores históricos, culturales y religiosos hacen que, en general, en el sistema interamericano, los Estados y los pueblos tengan una visión y aproximación similar a los derechos fundamentales. Justamente por esto, David Gómez Gamboa ha afirmado que "el sistema interamericano de protección de derechos ha constituido un verdadero 'corpus juris' interamericano que sirve de plataforma para la construcción del 'ius constitutionale commune' en Latinoamérica". ${ }^{70}$ Consecuentemente, se podría suponer que la tarea de la Corte IDH debería ser más sencilla que aquella de la Corte EDH.

Se ha argumentado que, a través del control de convencionalidad, la Corte IDH intenta establecer en términos jurisprudenciales la primacía del derecho interamericano de los derechos humanos. ¿Realmente intenta hacerlo? Con el control de convencionalidad, la Corte IDH solo les recuerda a los Estados partes que deben cumplir con sus obligaciones internacionales libremente asumidas. ¿Con esto intenta hacer primar su criterio? No directamente. Con todo, una consecuencia posible de este control es que la Corte IDH logre que los Estados y, sobre todo, que los jueces apliquen el derecho interamericano con prevalencia frente al derecho estatal. Esto produce una consecuencia no solo de primacía, sino también de efecto directo del derecho interamericano en relación con el derecho nacional. Como se ha mencionado, una consecuencia que es similar a lo que logró el Tribunal de Justicia de la Unión Europea en los años setenta.

De este modo, Gómez Gamboa ha sostenido que una especie de solución global y armoniosa de los conflictos vinculados a derechos humanos sería a través del 'ejercicio de un control 'primario' de convencionalidad

70 Gómez Gamboa, “Hacia un ius constitutionale...”, op. cit., p. 455. 
por parte de todas las autoridades nacionales y, eventualmente, a través del control 'complementario' de convencionalidad en sede internacional". ${ }^{71}$ En este sentido, en palabras de Eduardo Ferrer Mac-Gregor,

[1]a articulación dinámica y evolutiva entre el control primario y el control complementario de convencionalidad produce un nuevo entendimiento del sistema interamericano de protección de los derechos humanos al concebirse ahora como un 'sistema integrado', debido a que involucra no sólo a los dos órganos de protección a que se refiere la Convención Americana —Comisión y Corte IDH—, sino ahora comprende con particular intensidad y de manera concomitante a todas las autoridades nacionales de los Estados parte del Pacto de San José, al deber participar activamente en la garantía efectiva de los derechos humanos, sea en su dimensión nacional o internacional a manera de un 'sistema integrado' de protección de derechos. ${ }^{72}$

Una de las características que facilita y potencia el control de convencionalidad en el constitucionalismo contemporáneo es la apertura constitucional hacia el derecho internacional. Con las normas que se han ido incorporando en las constituciones nacionales,

se introduce [sic] una cláusula de apertura de los derechos fundamentales hacia los derechos humanos reconocidos internacionalmente cuya finalidad es garantizar, en cualquier caso, un estándar o contenido mínimo de los derechos, tal como son reconocidos en los tratados internacionales. Es por tanto al mismo tiempo un mínimo irrenunciable protegido por el poder constituyente y un mínimo en constante evolución, lo que cobra particular importancia en relación a aquellos Tratados que tienen un órgano judicial que los interpreta y actualiza, como el Tribunal Europeo de Derechos Humanos y la Corte Interamericana. ${ }^{73}$

${ }^{71}$ Ibíd., p. 452.

72 Corte IDH, Supervisión de cumplimiento de sentencia en el caso Gelman vs. Uruguay, resolución de la Corte Interamericana de Derechos Humanos del 20 de marzo de 2013, voto razonado del juez Eduardo Ferrer Mac-Gregor Poisot a la resolución de la Corte Interamericana de Derechos Humanos del 20 de marzo de 2013, para. 99.

73 Santolaya, Pablo, "La apertura de las constituciones a su interpretación conforme a los tratados internacionales", en Martin Retortillo Baquer, Lorenzo; Ferrer Mac-Gregor, Eduardo \& Herrera García, Alfonso (Coords.), Diálogo jurisprudencial en derechos bumanos. 
De esta manera, el constitucionalismo global incide en la interacción entre el derecho interno y el derecho internacional en un doble sentido. Por un lado, implica abrir el derecho constitucional y sus conceptos a la escena internacional y, por otro, "trasladar las garantías convencionales previstas en los tratados internacionales, al campo constitucional de tutela y salvaguarda de los derechos humanos, influenciando, inclusive, la práctica de las cortes nacionales". ${ }^{74}$

Un ejemplo patente de esto lo constituye una sentencia dictada por la Corte Suprema de Chile, a propósito del tratamiento prodigado por Gendarmería — que es el servicio a cargo del cuidado de los internos en las cárceles - a un interno en situación de discapacidad. Para el análisis de este caso, en relación con el control de convencionalidad, debería tenerse presente que, según la jurisprudencia interamericana, este control debe ser efectuado por los órganos internos y los jueces de todo nivel ex officio, otorgándole un efecto útil y efectivo a la convención o tratado, y los órganos internos, incluidos los jueces, deben efectuar dicho control, dentro de sus respectivas competencias. Teniendo esto en mente, resulta de la mayor importancia que la Corte Suprema chilena haya sostenido en este caso lo siguiente:

por otra parte, ocurre que la Convención sobre Derechos de las Personas con Discapacidad señala como obligaciones generales en su artículo cuarto, que los Estados partes se comprometen a asegurar y promover el pleno ejercicio de todos los derechos humanos y las libertades fundamentales de las personas con discapacidad sin discriminación alguna. "A tal fin, los Estados se comprometen a: f) emprender o promover la investigación y el desarrollo de bienes, servicios, equipo e instalaciones de diseño universal [...] para satisfacer las necesidades específicas de las personas con discapacidad, promover su disponibilidad y uso, y promover el diseño universal en la elaboración de normas y directrices"; y en su artículo $14 \mathrm{~N}^{\mathrm{0}}$ 2, donde señala que "los Estados partes asegurarán que las personas con discapacidad que se vean privadas de libertad en razón de un proceso tengan, en igualdad de condiciones que las demás, derecho a garantías de conformidad con los objeti-

Entre tribunales constitucionales y cortes internacionales, Tirant lo Blanch, Madrid, 2013, pp. 447456, especialmente p. 449.

74 Cardoso Campos, "Controle de convencionalidade...”, op. cit., p. 52. 
vos y principios de la presente convención, incluida la realización de ajustes razonables". Estas disposiciones deben orientar el trato que Gendarmería debe dar a los internos en cumplimiento del respeto a las garantías constitucionales de que ellos gozan. ${ }^{75}$

Por otro lado, la doctrina ha destacado, a propósito del control de convencionalidad, las funciones vitales de la Corte IDH, resaltando la función decisoria de la litis como garante de los derechos de la víctima en la controversia y una función interpretativa de la CADH como garante de los principios que integran el sistema interamericano de protección de los derechos humanos. ${ }^{76}$

Así, en primer término, tendríamos la eficacia subjetiva directa de la sentencia hacia las partes (res judicata). La 'res judicata' y el 'control de convencionalidad' aparecen cuando en "una sentencia de la Corte IDH se ha determinado la responsabilidad internacional de un Estado, la autoridad de la cosa juzgada produce, necesariamente, vinculación absoluta en la manera en que las autoridades nacionales del Estado condenado deben interpretar la norma convencional y, en general, el corpus iuris interamericano aplicado en la sentencia que decide el caso". ${ }^{77}$

En segundo lugar, aparecería la eficacia interpretativa objetiva indirecta de la norma convencional (res interpretata) hacia todos los Estados

75 Corte Suprema, Amparo de presos discapacitados, Rol No 26.492-2014, 30 de octubre de 2014, considerando 4.

76 "Asimismo, la sentencia debió avanzar en un desarrollo jurisprudencial más profundo de la propia Carta Democrática Interamericana, en específico, en relación a lo que consagra su artículo 3. La función contenciosa del Tribunal Interamericano consiste en resolver las controversias que la Comisión Interamericana y las partes le proponen en un caso en concreto; es indudable que también tiene como misión ser garante de los principios que integran el Sistema Interamericano de Derechos Humanos. Esto se logra, guiando con la interpretación el significado de dichos principios, a fin de esclarecerlos. De tal suerte, que decidir la litis y el alcance del derecho entre las partes es uno de los cometidos de la jurisdicción interamericana, pero no el único, ya que también tiene a su cargo la función interpretativa de la Convención Americana, cuya importancia se incrementa a partir del muy reducido número de casos de los que conoce". Corte IDH, Caso de la Corte Suprema de Justicia (Quintana Coello y otros) vs. Ecuador, sentencia del 23 de agosto de 2013, voto concurrente del juez Eduardo Ferrer Mac-Gregor Poisot a la sentencia de la Corte Interamericana de Derechos Humanos en el caso Corte Suprema de Justicia (Quintana Coello y otros) vs. Ecuador, del 23 de agosto de 2013, para. 63.

77 Gómez Gamboa, “Hacia un ius constitutionale...”, op. cit., p. 452. 
partes de la Convención Americana. En esta línea, Ferrer Mac-Gregor ha sostenido que:

el Tribunal Interamericano tiene en los tiempos actuales una función interpretativa erga omnes de la Convención Americana más allá del caso particular [...]. Así, en la justicia interamericana adquiere una particular relevancia la expansión vinculante de la 'norma convencional interpretada' más allá del caso particular (res interpretata), constituyendo un elemento más en la construcción de un ius constitutionale commune americanum —o por lo menos y por ahora latinoamericanum —, que permita garantizar un estándar mínimo de aplicabilidad regional de la Convención Americana en favor de los derechos y la dignidad humana. ${ }^{78}$

En relación con la 'res interpretata' y el 'control de convencionalidad', como segunda manifestación del ejercicio del 'control de convencionalidad' en sede nacional, esta se produce cuando los demás Estados partes del Pacto de San José aplican la jurisprudencia interamericana derivada de aquellos casos en que no han sido partes. En este sentido, "adquiere eficacia interpretativa la norma convencional hacia los demás Estados parte de la Convención Americana (res interpretata). La eficacia vinculante de la 'norma convencional interpretada' constituye una obligación convencional derivada de los artículos $1^{\circ}$ y $2^{\circ}$ de la Convención Americana”. ${ }^{79}$

Esto nos permite vincular el control de convencionalidad con diálogo entre jueces. Tradicionalmente, el diálogo entre jueces en materia de derechos humanos se ha planteado junto con el control de convencionalidad. Una de las preguntas que se pueden plantear a este respecto es, si el ejercicio del control de convencionalidad es una obligación para los Estados partes, podría a esto denominársele, propiamente tal, diálogo entre jueces. El diálogo no implica el cumplimiento de obligaciones de acatamiento, ello simplemente es un deber de cumplimiento. Habría diálogo en la medida que la argumentación de un tribunal no es obligatoria para otro tribunal, sino más bien el diálogo responde a una labor de convencimiento o de persuasión en los argumentos y en el razonamiento jurídico. En estos casos, el argumento y razonamiento de otros jueces resultan siendo

\footnotetext{
78 Corte IDH, Caso de la Corte Suprema de Justicia (Quintana Coello y otros) vs. Ecuador, op. cit., para. 79 .

79 Gómez Gamboa, “Hacia un ius constitutionale...”, op. cit., p. 453.
} 
seguidos, normalmente, por el peso convincente de la argumentación, pero no porque sean obligatorios para los jueces.

Este control de convencionalidad se podría mencionar como un ejemplo de un constitucionalismo global en la medida que requiere un Estado abierto y, en términos de Häberle, un Estado constitucional cooperativo. ${ }^{80}$ Desde el punto de vista del enfoque de la argumentación y juicio jurisdiccional, el Estado abierto

[n]o se trata, por tanto, de integrar con nuevos derechos supuestas lagunas originarias o sobrevenidas de los textos constitucionales, sino de garantizar una interpretación de los derechos constitucionales por parte de todos los operadores jurídicos que sea, al menos, internacionalmente homologable, lo que se ha denominado una interpretación internacionalmente conforme, nunca por debajo del estándar internacional, aunque naturalmente puede estar por encima. ${ }^{81}$

Este tipo de constitucionalismo revela "la actual tendencia en el constitucionalismo mundial a prestigiar las normas internacionales destinadas a la protección del ser humano". ${ }^{82}$ Aun cuando hay corrientes que apuntan a simplificar el control de convencionalidad, reduciéndolo a la aplicación del DIDH, es evidente que en este control hay muchos más elementos en juego.

Todo este desarrollo teórico, en cierta medida propositivo y diagnóstico, en crecientes ocasiones se puede palpar en la práctica judicial, tanto nacional como internacional. A continuación, examinaremos dos casos relativos a los derechos sociales, en donde intentaremos verificar si se realiza un control de convencionalidad, si este control refleja potencialmente una manifestación del constitucionalismo global y el camino hacia la conformación de un ius constitutionale commune interamericanum.

80 Häberle, El Estado constitucional, op. cit., pp. 68-69.

81 Santolaya, "La apertura de las constituciones...", op. cit., p. 450.

82 Ferreira Mendes, "La doctrina de un derecho...", op. cit., p. 70. 


\section{El ejemplo del derecho humano a la huelga en Chile}

En esta parte, queremos referirnos sucintamente a dos ejemplos chilenos sobre el derecho a huelga que ha conocido recientemente la Corte Suprema y que, a nuestro entender, podría bien constituir una manifestación de los procesos que representan las nociones de constitucionalismo global e ius constitutionale commune interamericanum. Como ya se ha expresado, aquí hablamos de ius constitutionale commune, porque los derechos humanos son entendidos como elementos básicos de carácter constitucional. Y hablamos de interamericanum, porque este común entendimiento de los derechos humanos se produce, básicamente aun cuando no exclusivamente, a partir de las instituciones y de las normas que componen el sistema interamericano de protección de los derechos humanos. En este sentido, habría que reconocer que la amplia mayoría de los Estados que forman parte del sistema son latinoamericanos. Con todo, este entendimiento común no se produce exclusivamente a partir del sistema interamericano, sino que incluye la consideración de instrumentos y jurisprudencia que van más allá del sistema interamericano, porque los derechos humanos constituyen un sistema jurídico integral e integrado, universal, indivisible e interrelacionado, imposible de segmentar geográficamente, de modo que siempre el entendimiento latinoamericano de los derechos humanos incluirá la comprensión universal, internacional y comparada de los derechos.

\subsection{La jurisprudencia evolutiva de la Corte Suprema}

El primer caso analizado corresponde a Inspección Comunal del Trabajo con Promolinks S.A. (caso Promolinks) sobre prácticas desleales y/o antisindicales en perjuicio del Sindicato de Trabajadores de Empresa Promolinks S.A., iniciado por la Inspección Comunal del Trabajo Santiago Sur Oriente. En este caso, se declaró la efectividad de la práctica antisindical y se impuso una multa a la empresa Promolinks. En el contexto de una declaración de huelga, el empleador respondió 'reemplazando' a algunos "dependientes en huelga; que lo hizo destinando a las labores a cargo de los protestantes, a otros dependientes suyos, situados normalmente en otras sedes o locales desde antes del comienzo del proceso de negociación colectiva". Con esto no solo se denunció una práctica antisindical, sino además una transgresión a la ley en materia de huelga. Los hechos fueron constatados por fiscalizadores de la Inspección Comunal del Trabajo de Santiago Sur Oriente (Rol No 3514-2014). 
El segundo caso corresponde a Inspección Comunal del Trabajo con Carvajal Empaques S.A. (caso Carvajal Empaques) sobre prácticas desleales en la negociación colectiva ya que el empleador, durante la negociación, reemplazó ilegalmente a trabajadores en huelga. El empleador sostuvo que no incurrió en este tipo de conductas, sino que simplemente redistribuyó y asignó de manera más eficiente sus limitados recursos, pero no contrató nuevos trabajadores ( $\left.R o l N^{\circ} 10.444-2014\right)$.

Tanto en el caso Promolinks como en el caso Carvajal Empaques se trata de una situación de reemplazo de trabajadores en huelga con trabajadores internos de la misma empresa, sin contratar nuevos trabajadores. En estos casos, la Corte Suprema tuvo que razonar sobre la base de verificar si esta situación era vulneradora del derecho a huelga. Veremos a continuación cuál fue el razonamiento del juez supremo, si recurrió o no al derecho internacional de los derechos humanos y al derecho comparado, y si efectivamente recurrió, cómo lo hizo.

En el caso Promolinks con fecha 4 de diciembre de 2014, la Corte Suprema de Chile en un fallo dividido, 3 votos a favor y 2 en contra, se pronunció por rechazar el reemplazo de trabajadores en caso de huelga, ya sea reemplazados por trabajadores de la misma empresa o nuevos trabajadores contratados, fortaleciendo de esta manera, el derecho humano a huelga. Lo que a nosotros nos interesa rescatar de aquí, de la argumentación que realiza la Corte Suprema, es el desarrollo del derecho humano a la huelga tomando como base un análisis contextual histórico, la aportación de los procesos de globalización social y económica y, sobre todo, la consideración del derecho internacional de los derechos humanos en el contexto de la realización de un control de convencionalidad. A partir de esta apertura jurídica de los jueces de la Corte Suprema, se ha podido avanzar un poco en la protección de los trabajadores en la relación laboral, por la vía del control de convencionalidad, adecuándose al estándar mínimo que el DIDH establece. Una sentencia similar pronunció la misma Corte Suprema, algunos meses más tarde, en el sentido de rechazar la posibilidad del reemplazo interno en casos de ejercicio del derecho a huelga. Este es el caso Carvajal Empaques del 29 de enero de 2015, donde el fallo se acordó por 4 votos contra 1.

Primeramente, desde el enfoque conceptual, la Corte Suprema, tanto en Promolinks como en Carvajal Empaques, coincide en un concepto jurisprudencial de huelga, a saber: 
que, del mismo modo, se debe señalar que la huelga se conceptualiza como el rechazo de los trabajadores de una unidad productiva a prestar los servicios a que se encuentran obligados en circunstancias normales. Está regulada como variante de un proceso de negociación a cargo de un colectivo de dependientes legalmente organizados en sindicatos, ante el fracaso de las tratativas tendientes a la obtención de mejorías en sus derechos. Es universalmente concebida como la vía inevitable para impulsar el entendimiento inter partes, pues presupone como elemento de su esencia, sin el cual degenera en cosa distinta, el riesgo del propietario, apremiado por la urgencia de reactivar el ente transitoriamente paralizado, contra su voluntad..$^{83}$

En nuestra opinión en este caso, el máximo tribunal del país a través de su práctica jurisdiccional, efectúa un control de convencionalidad. En este sentido, lo más relevante de esta sentencia es que los jueces de la Sala Laboral se apoyan, para la justificación de su razonamiento, en el derecho internacional de los derechos humanos. Así, en el ámbito universal se menciona la Carta Internacional de Derechos Humanos compuesta por la Declaración Universal de Derechos Humanos, ${ }^{84}$ por el Pacto Internacional de Derechos Civiles y Políticos, y por el Pacto Internacional de Derechos Económicos, Sociales y Culturales. ${ }^{85}$ Adicionalmente, la sentencia parece referirse a los convenios pertinentes de la Organización Internacional del Trabajo (en adelante, la OIT). En el ámbito regional, se menciona la Carta Internacional Americana de Garantías Sociales de 1948 y el Protocolo Adicional a la Convención Americana sobre Derechos Humanos en Materia de Derechos Económicos, Sociales y Culturales, adoptado en

83 Corte Suprema, Inspección Comunal del Trabajo Norte Chacabuco con Carvajal Empaques S.A., procedimiento de tutela laboral, Rol No 10.444-2014, sentencia del 29 de enero de 2015, considerando 10; Corte Suprema, Sindicato de Trabajadores de Empresa Promolinks S.A., procedimiento de tutela laboral, Rol N³.514-2014, sentencia del 4 de diciembre de 2014, considerando 11 .

84 "La Declaración, como todo texto clásico, no es un instrumento anclado en el pasado y referido sólo a un momento histórico. Es, por el contrario, un documento vivo, abierto al progreso y destinado a promover la recepción de las nuevas ideas y de las nuevas reglas exigidas por un mundo en constante proceso de cambio". Gros Espiell, "Una mirada actual...", op. cit., p. 79.

85 Corte Suprema, Sindicato de Trabajadores de Empresa Promolinks S.A., op. cit., considerando 17; Corte Suprema, Inspección Comunal del Trabajo Norte Chacabuco con Carvajal Empaques S.A., op. cit., considerando 15. 
San Salvador en $1988 .{ }^{86}$ A propósito de este uso, como justificación de su argumentación, de fuentes internacionales en el juicio jurisdiccional, la Corte Suprema se refiere a una de las reglas de oro de la relación entre derecho internacional y derecho interno, señalando que:

es el momento oportuno para recordar aquella regla elemental en la convivencia jurídica de la comunidad de las naciones, que se encuentra estampada en el artículo 27 de la Convención de Viena sobre el Derecho de los Tratados, de acuerdo con la cual "una parte no podrá invocar las disposiciones de su derecho interno como justificación del incumplimiento de un tratado". Esta norma se entenderá sin perjuicio de lo dispuesto en el artí́culo $46 .{ }^{87}$

De este modo, la Corte Suprema nuevamente da lecciones de uso del plexo de fuentes formales del derecho internacional, en este caso particularmente, de las fuentes convencionales. ${ }^{88}$ Con todo, la Corte Suprema podría haber incrementado el uso de este tipo de fuentes en las que funda su decisión. ¿Qué le faltó a la Corte Suprema? Le faltó referirse a una serie de instrumentos jurídicos internacionales que los Estados han suscrito o adoptado y que abordaremos en el epígrafe siguiente.

Finalmente, coincide con la visión antes expresada del constitucionalismo global, la toma en consideración, por los jueces de la Corte Suprema, de las aportaciones de los procesos de globalización social y económica. Así, esta Corte menciona tanto en Promolinks como en Carvajal Empaques:

La escueta evolución del tratamiento del derecho a la huelga [...] revela que a partir de mediados del siglo xx la comunidad interamericana se compromete con el derecho a la huelga de los trabajadores; que impone a los Estados partes el deber de respetarlo; que lo privilegia con

86 Corte Suprema, Sindicato de Trabajadores de Empresa Promolinks S. A., ibíd., considerandos 18 y 19; Corte Suprema, Inspección Comunal del Trabajo Norte Chacabuco con Carvajal Empaques S.A., ibíd., considerando 16.

87 Corte Suprema, Sindicato de Trabajadores de Empresa Promolinks S. A., ibíd., considerando 20; Corte Suprema, Inspección Comunal del Trabajo Norte Chacabuco con Carvajal Empaques S.A., ibíd., considerando 18.

88 Ver Aguilar Cavallo, Gonzalo, "La Corte Suprema y la aplicación del derecho internacional: un proceso esperanzador”, Estudios Constitucionales, 2009, 7, (1), pp. 91-136. 
el halo de la irrenunciabilidad; y que prohíbe regularlo mediante leyes que terminen por abolirlo.

Entretanto, en el Chile contemporáneo comienza mirándoselo con desconfianza, como un mal necesario que hay que formalizar, empero en lo posible no practicar; para evolucionar hacia una cierta tolerancia o mayor permisividad; y rematar con un discurso acorde con los parámetros de ese derecho universal al que el país se halla adscrito, consciente de los severos supracontroles a que está sujeto.

Para los efectos exegéticos de nuestra preocupación, lo rescatable viene siendo la constatación de una tendencia histórico-normativa hacia la plena reafirmación de la huelga como principio básico del catálogo de derechos económicos sociales y culturales y como prerrogativa irrenunciable del derecho laboral, aunque por sí solo este elemento hermenéutico no nos aporte de manera determinante en punto a la legitimidad del reemplazo en las circunstancias inicialmente descritas. ${ }^{89}$

Entonces, ¿por qué, por regla general, no cabe el reemplazo en el contexto del ejercicio del derecho de huelga? La Corte Suprema, en el caso Carvajal Empaques, nos aporta una respuesta:

[A]l producirse la referida sustitución se atenta contra la huelga acordada, en la medida que si existe la posibilidad de designar a otros trabajadores para que realicen las labores cuyo cometido corresponde a los huelguistas, la paralización por parte de estos deja de constituir la instancia necesaria para forzar un acuerdo con el empleador y, en mayor o menor grado, contraría el derecho a la asociación, garantizado constitucionalmente, desde que el objetivo perseguido a través de la organización o constitución de un sindicato se ve mermado ante la imposibilidad de ejercer en plenitud las finalidades del ente sindical. ${ }^{90}$

Además, los jueces del máximo tribunal, aplicando el principio pro bomine, reconocen el principio de la protección del contratante débil, en este caso, en la relación laboral. Esta se constituiría en la tendencia moderna de

\footnotetext{
89 Corte Suprema, Sindicato de Trabajadores de Empresa Promolinks S.A., op. cit., considerando 21; Corte Suprema, Inspección Comunal del Trabajo Norte Chacabuco con Carvajal Empaques S.A., op. cit., considerando 19.

90 Corte Suprema, Inspección Comunal del Trabajo Norte Chacabuco con Carvajal Empaques S.A., ibíd., considerando 25.
} 
la Sala Laboral de la Corte Suprema y se pone en línea con las enseñanzas derivadas de un ius constitutionale commune interamericanum y con el camino propio del constitucionalismo global. ${ }^{91}$

Este razonamiento se encuentra en armonía con los estándares establecidos por los instrumentos internacionales de derechos humanos, los que han sido ratificados por la interpretación que se ha hecho de ellos por parte de los órganos autorizados. ${ }^{92}$

Resulta interesante destacar que, en Carvajal Empaques, el abogado integrante Prado, en su voto disidente, realiza efectivamente un control de convencionalidad lato sensu, ya que no solo recurre al control de los instrumentos positivos internacionales, sino que además usa como parámetro la interpretación que de dichas convenciones internacionales ha realizado la Comisión de Expertos de la OIT. Aun cuando se puede discrepar de su posición, es interesante destacar cómo el control de convencionalidad puede ser esgrimido por los jueces nacionales para sostener posiciones opuestas. ${ }^{93}$

91 "De esta manera, aun ante el silencio de la ley en la asignación expresa del régimen de responsabilidad al que se encuentra sujeto el dueño de obra cuando es demandado conjuntamente con el contratista, cada uno en virtud de la infracción de sus respectivos deberes que hicieron posible un único resultado lesivo, la comprensión conjunta de las disposiciones mencionadas bajo el prisma interpretativo propio del derecho laboral que permite a los jueces la asignación de sentido de sus disposiciones conforme el criterio pro operario que posibilita la integración de las normas que regulan una misma materia, fuerza a concluir que tal estatuto es el propio de la solidaridad, con los matices que el derecho laboral introduce en su comprensión, conforme se advierte de los términos de la propia Ley 20.123. En razón de lo concluido, no puede conculcarse con lo resuelto los artículos 1511 y 1526 del Código Civil, por cuanto la interpretación que se ha dado a las normas en análisis es la que permite su máxima expresión protectora, coherente con los fines tenidos en consideración para su elaboración". Corte Suprema, Molina Aguilera con Comercial Sepmo y Cía. Ltda. y otros, recurso de unificación de jurisprudencia, Rol No 10.139-2013, sentencia de fecha 10 de junio de 2014, considerando 8 .

92 "Además, todas las medidas de carácter deliberadamente retroactivo en este aspecto requerirán la consideración más cuidadosa y deberán justificarse plenamente por referencia a la totalidad de los derechos previstos en el Pacto y en el contexto del aprovechamiento pleno del máximo de los recursos de que se disponga". Comité de Derechos Económicos, Sociales y Culturales, Observación General No 3, La indole de las obligaciones de los Estados partes, quinto período de sesiones (1990) (párrafo 1 del artículo $2^{\circ}$ del Pacto).

93 "Que el derecho a huelga como tal no aparece mencionado de manera expresa en algunas de las fuentes consultadas más reconocidas tales como el texto vigente del 'Preámbulo de la Constitución de la OIT' (Oficina Internacional del Trabajo, Ginebra, 2010, p. 5) tampoco en la 'Declaración de Filadelfia de 1944' relativa a los fines y objetivos de la Organización Internacional del Trabajo. De igual manera, no consta en la aplicación de los 
Luego, en su conclusión, la Corte Suprema reconoce al derecho internacional de los derechos humanos, pero también los elementos de contexto histórico, evolutivo, sociológico y sociocultural, como 'fuentes' de su juicio jurisdiccional. Incluso, en esta conclusión, queda plasmada la relevancia del rol que juega el juez en un Estado constitucional democrático del siglo XXI y, como consecuencia, la importancia de su argumentación justificativa:

al culminar el recorrido presentado en el razonamiento $9^{\circ}$ de este documento, se constata que de las dos maneras de aprehender el sentido más profundo y holístico del discurso legal del tantas veces mencionado artículo 381 del Código del Trabajo, la balanza se inclina en favor del que cierra absolutamente las puertas a toda suerte de reemplazo de los trabajadores en huelga, aun, por cierto, el consistente en traer desde otros lugares de la misma cadena en conflicto, trabajadores que releven a los paralizados, conclusión ésta que sin pretenderse invalidadora de la postura plasmada en las sentencias de cotejo, es fruto del empleo consciente y responsable de las fuentes que alimentan el juicio jurisdiccional, para discernir con el mejor de los grados de acierto posible, cuál sea la línea que en asuntos tan importantes para la convivencia social convenga que asuman los tribunales. ${ }^{94}$

¿Por qué los casos mencionados precedentemente de la Corte Suprema de Chile constituyen un ejemplo de control de convencionalidad? Si aceptamos la premisa básica que el control de convencionalidad implica para los jueces nacionales —en una versión más ligera que la fórmula de la

distintos convenios de la OIT una práctica que acredite la existencia de un acuerdo entre sus partes para interpretar que algún convenio de la organización ampare el derecho de huelga ni su forma de aplicación; los pronunciamientos en cuanto a este aspecto corresponden a la denominada 'Comisión de Expertos', instancia técnica creada en 1944 sin carácter decisorio destinada a la aplicación de convenios y recomendaciones destinadas a dicha entidad internacional. Al respecto cabe señalar que si bien para la referida 'Comisión de Expertos' la contratación de trabajadores para romper la huelga y la utilización de mano de obra ajena resulta contraria al principio denominado de la 'libertad sindical', en todo caso no se declara contrario a la sustitución interna”. Corte Suprema, Inspección Comunal del Trabajo Norte Chacabuco con Carvajal Empaques S.A., op. cit., voto disidente del abogado integrante Sr. Prado, considerando 5.

94 Corte Suprema, Sindicato de Trabajadores de Empresa Promolinks s.A., op. cit., considerando 36. 
Corte IDH— la obligación de velar en el ámbito interno de los Estados por el respeto de las obligaciones convencionales que el Estado ha contraído, entonces, podríamos afirmar que lo que la Corte Suprema en estos casos es, inter alia, un control de convencionalidad.

Los casos reseñados sobre el derecho a huelga demuestran las potencialidades que presenta para la protección de los derechos humanos, individuales y colectivos, la realización de un control de convencionalidad, y por lo tanto, el uso de un enfoque dinámico y abierto al mundo global por parte de los jueces. En este caso, la Corte Suprema no solo ha aplicado una vez más, el derecho internacional de los derechos humanos, sino que abre el Estado a la cooperación, asumiendo la senda del ius commune interamericano e insertándose en el contexto de un constitucionalismo global.

\subsection{Los instrumentos internacionales y la protección de la dimensión colectiva del trabajo}

La Corte Suprema chilena recurre intensivamente en su argumentación, en los casos Promolinks y Carvajal Empaques, al derecho internacional de los derechos humanos e incluso, al derecho internacional clásico, cuando se refiere a las normas de la Convención de Viena sobre el Derecho de los Tratados de 1969.

Como se ha sostenido, el uso de instrumentos internacionales por parte de los jueces nacionales constituiría un rasgo de constitucionalismo global y un paso en la construcción del ius commune basado en los derechos humanos. Junto con ello, si el juez nacional usa el derecho convencional internacional como parámetro de control y contraste con la norma interna, con el objeto de formar su razonamiento y alcanzar su decisión, entonces, el juez nacional estaría efectuando un control de convencionalidad. ¿Cuáles serían los instrumentos mencionados en los casos analizados?

Por el lado de los instrumentos jurídicos de hard law (derecho vinculante), hay que comenzar refiriéndose a los principios y derechos fundamentales reconocidos en la Constitución de la Organización Internacional del Trabajo (OIT), adoptada originalmente en 1919, y en la Declaración de Filadelfia del 10 de mayo de 1944, anexa a ella. Junto con lo anterior, se encuentran los convenios fundamentales que contienen el núcleo duro de los derechos humanos en el trabajo, tales como el Convenio 87 de 1948 sobre la libertad sindical y la protección del derecho de sindicación de la 
Organización Internacional del Trabajo; ${ }^{95}$ el Convenio 98 de 1949 sobre el derecho de sindicación y de negociación colectiva de la Organización Internacional del Trabajo; ${ }^{96}$ el Convenio 151 de 1978 sobre la protección del derecho de sindicación y los procedimientos para determinar las condiciones de empleo en la administración pública; ${ }^{97}$ y el Convenio 154 de 1981 sobre la negociación colectiva de la Organización Internacional del Trabajo. ${ }^{98}$ En esta línea, la OIT ha sostenido que "[e]l derecho de huelga ha sido reconocido internacionalmente como un derecho fundamental de los trabajadores y de sus organizaciones y como un corolario indisociable del derecho de sindicación. Sin embargo, aún hay en todo el mundo millones de personas que no gozan de esos derechos, e incluso cuando estos son reconocidos, siguen presentándose obstáculos para su aplicación". ${ }^{99}$ Por su parte, Bernard Gernigon, Alberto Odero y Horacio Guido han destacado entre los principios del derecho a huelga, por un lado:

[e]l reconocimiento con carácter general del derecho de huelga a los trabajadores del sector público y del sector privado. Solamente es admisible hacer excepciones de este derecho (o someterlo a restricciones importantes) respecto de los miembros de las fuerzas armadas y de la policía, los funcionarios públicos que ejercen funciones de autoridad en nombre del Estado y los trabajadores de los servicios esenciales en el sentido estricto del término (aquellos cuya interrupción podría poner en peligro la vida, la seguridad o la salud de toda o parte de la población), o en situaciones de crisis nacional aguda.

Por otro lado, "[1]a contratación de trabajadores en sustitución de huelguistas menoscaba gravemente el derecho de huelga, y sólo es admisible en caso de huelga en un servicio esencial o en situaciones de crisis nacional aguda". ${ }^{100}$ Por último, desde 1952, la OIT ha reconocido el "derecho de

95 Ratificado por Chile el $1^{\circ}$ de febrero de 1999.

96 Ibíd.

97 Ratificado por Chile el 17 de julio de 2000.

98 Aún no ratificado por Chile.

99 OIT, "Libertad de asociación y la libertad sindical y el reconocimiento efectivo del derecho de negociación colectiva", en http://ilo.org/declaration/principles/freedomofassociation/lang--es/index.htm, consulta del 12 de diciembre de 2014.

100 Gernigon, Bernard; Odero, Alberto \& Guido, Horacio, Principios de la OIT sobre el derecho 
huelga como un derecho legítimo al que pueden recurrir los trabajadores y sus organizaciones en defensa de sus intereses económicos y sociales", y, además, que el "derecho de huelga es corolario indisociable del derecho de sindicación protegido por el Convenio núm. 87 ". ${ }^{101}$

Por otra parte, y en particular, en relación con el Convenio 87 de 1948 sobre la libertad sindical y la protección del derecho de sindicación de la OIT y la posibilidad de restringir este derecho, cabe señalar que el Tribunal Constitucional chileno, en una decisión que arrojó un empate, en el voto de 5 jueces por acoger el recurso, se afirmó — correctamente a nuestro modo de ver- que la prohibición para ejercer el derecho de sindicación y gozar de todas las facultades que otorga la libertad sindical exigía una interpretación restrictiva, "puesto que obliga al intérprete a verificar hasta qué punto se han de aplicar las reglas excepcionales del convenio". ${ }^{102}$

Por el lado de los instrumentos jurídicos de soft law (derecho no directamente vinculante), se podría haber recurrido a la Declaración de Copenhague sobre Desarrollo Social de 1995. También, a la Declaración de la OIT Relativa a los Principios y Derechos Fundamentales en el Trabajo de 1998. Desde el punto de vista del constitucionalismo global y el papel de los derechos humanos, nótese la potente alusión al rol constitucional de

\footnotetext{
de buelga, Oficina Internacional del Trabajo, Ginebra, 2000, pp. 58-59.

101 OIT, Libertad sindical. Recopilación de decisiones y principios del Comité de Libertad Sindical del Consejo de Administración de la OIT, $5^{\mathrm{a}}$ edición revisada, Oficina Internacional del Trabajo, Ginebra, 2006, paras. 521-523.

102 "Que, en esta perspectiva, resulta fundamental citar el Convenio 87 de la Organización Internacional del Trabajo [Convenio sobre la Libertad Sindical y la Protección del Derecho de Sindicación de 1948], que exige una interpretación restrictiva de esta prohibición, puesto que obliga al intérprete a verificar hasta qué punto se han de aplicar las reglas excepcionales del Convenio;

Que, en consecuencia, sólo una justificación expresa y circunstanciada permite acreditar la legitimidad de la restricción sobre un derecho fundamental como el derecho de asociación; Que, habida cuenta del principio establecido, el ordenamiento constitucional entrega libertad al legislador para establecer el procedimiento para constituir asociaciones con personalidad jurídica, eso sí, condicionada a no afectar la esencia del derecho aludido". Tribunal Constitucional de Chile, Requerimiento de inaplicabilidad por inconstitucionalidad presentado por el Juzgado de Letras del Trabajo de Concepción respecto del inciso segundo del artículo $1^{\circ}$ de la Ley 19.296, en los autos RIT I-36-2010, RUC 10-4-0032869-8 sobre reclamación de resolución administrativa sustanciados ante el Juggado de Letras de Concepción, Rol No 1790-10, sentencia de fecha 4 de octubre de 2011, voto por acoger de los ministros señores Hernán Vodanovic Schnake, Francisco Fernández Fredes, Carlos Carmona Santander, José Antonio VieraGallo Quesney y Gonzalo García Pino, considerandos 8, 9 y 10.
} 
la Organización y de los derechos fundamentales en el trabajo, afirmado por los Estados en el preámbulo de la Declaración: "Considerando que la OIT es la organización internacional con mandato constitucional y el órgano competente para establecer normas internacionales del trabajo y ocuparse de ellas, y que goza de apoyo y reconocimiento universales en la promoción de los derechos fundamentales en el trabajo como expresión de sus principios constitucionales". Además, a la Declaración de la OIT sobre la Justicia Social para una Globalización Equitativa, adoptada el 10 de junio de 2008. En el plano regional, la Corte Suprema podría, ciertamente, haberse apoyado en la Carta Social de las Américas, aprobada por la Asamblea General de la Organización de Estados Americanos el 4 de junio de 2012. ${ }^{103}$

Todos estos instrumentos jurídicos internacionales son bien conocidos por empleadores y trabajadores, y por cierto, por los Estados, debido a que, por la composición tripartita de la OIT, todos los tres participan de los procesos de generación de estos instrumentos. De modo que, precisamente, lo que aquí sí hay es certidumbre y seguridad jurídica.

Además, los jueces del máximo tribunal recurren al derecho comparado, mencionando que Brasil, México, Colombia y Ecuador contienen normas prohibitivas del reemplazo de trabajadores en huelga. Así, agrega, “la instauración del 'rompehuelgas' se encuentra prohibida en el Código del Trabajo francés —artículo 124/2/3-, la Ley de Huelga portuguesa — artículo $6^{\circ}$ - , el Decreto Reglamentario de la Ley del Trabajo española —artículo 6.5- y otros de la zona europea". ${ }^{104} \mathrm{El}$ recurso al derecho comparado en la materia constitucional, y especialmente de derechos fundamentales, sería un elemento identificador del constitucionalismo global

103 El artículo $8^{\circ}$ de la Carta Social señala: "La promoción del trabajo decente, la reducción del desempleo y del subempleo y la atención a los desafíos del trabajo informal son elementos esenciales para alcanzar el desarrollo económico con equidad.

El respeto de los derechos de los trabajadores, la igualdad de oportunidades en el empleo y la mejora de las condiciones de trabajo son elementos esenciales para lograr la prosperidad. La cooperación y el diálogo social entre representantes de los gobiernos, los trabajadores, empleadores y otras partes interesadas promueven una buena gestión y una economía estable. El respeto de la Declaración de la Organización Internacional del Trabajo relativa a los Principios y Derechos Fundamentales en el Trabajo y su Seguimiento, de 1998, ayuda a fomentar una fuerza de trabajo de calidad que impulsa el progreso económico y social, el crecimiento sostenido y equilibrado y la justicia social para los pueblos del hemisferio".

104 Corte Suprema, Sindicato de Trabajadores de Empresa Promolinks S.A., op. cit., considerando 17. 
y del proceso de construcción de un ius commune basado en los derechos humanos. $^{105}$

\subsection{Las dificultades de conciliar la visión política con el razonamiento jurídico}

El día 21 de diciembre de 2015 se cumplen 108 años de una de las peores tragedias sociales y humanas que han ocurrido en la historia de las reivindicaciones sociales en Chile. Me refiero a la masacre de los obreros del salitre en la Escuela Santa María de Iquique en 1907. Ese día, más de 200 obreros fueron acribillados por agentes del Estado cuando realizaban una huelga en demanda de mejoras salariales y mejores condiciones de trabajo. El rechazo de las compañías a negociar generó la firme intervención estatal en contra de los huelguistas. ${ }^{106}$ En Chile, 108 años después de la masacre de Santa María, los trabajadores continúan reivindicando ante los órganos jurisdiccionales estatales su derecho humano a la huelga. ${ }^{107}$

En el editorial del domingo 7 de diciembre de 2014 del diario El Mercurio de Santiago, se comentó el denominado "supremazo", aludiendo al caso Promolinks, sentencia de fecha 4 de diciembre de 2014, que dictó la Sala Laboral de la Corte Suprema, a propósito del derecho humano a la huelga. El editorial critica el fallo, por no centrar su argumentación en la norma debatida, por realizar reflexiones sobre la relevancia del derecho a huelga, por referirse al derecho internacional de los derechos humanos y por afectar la certeza jurídica. Por esto dice que el fallo es contraproducente, aludiendo evidentemente, a la incertidumbre jurídica que genera. ${ }^{108}$

\footnotetext{
105 Häberle, "México y los contornos...", op. cit.

106 "Masacre de la Escuela Santa María de Iquique", en http://www.memoriachilena. cl/602/w3-article-3604.html\#presentacion, consulta del 15 de diciembre de 2014.

107 Sobre una visión actualizada del derecho a huelga en Chile, ver INDH, Informe anual sobre la situación de los derechos bumanos en Chile 2014, Santiago, 2014; CDH, Informe anual sobre derechos bumanos en Chile 2014, Ediciones Diego Portales, Santiago, 2014.

108 "El peso de la argumentación del fallo, sin embargo, no está puesto en el análisis de la norma, sino en reflexiones sobre el sentido de la huelga como herramienta indispensable de presión en la relación asimétrica de los trabajadores con el empleador. La sentencia destina numerosos considerandos a la evolución de la protección del derecho a la huelga en el derecho internacional del trabajo y los derechos humanos, mostrando cómo entre la implementación del denominado plan laboral y los tiempos actuales ha cambiado radicalmente el contexto interpretativo de las reglas sobre la huelga". "Supremazo' sobre reemplazo en huelga”, El Mercurio, domingo 7 de diciembre de 2014, p. A3.
} 
En otro editorial del día 12 de diciembre de 2014, de otro diario de importancia nacional, La Tercera, se formula igualmente, una áspera crítica al fallo de la Corte Suprema. Así, se indica que:

[1]o resuelto por el Tribunal Supremo introduce una nueva nota de inflexibilidad laboral y resulta discutible desde el punto de vista de su argumentación, ya que se basa en invocaciones de derechos genéricos y convenios internacionales que nada específico dicen sobre el reemplazo, y desatiende el tenor literal de la normativa legal aplicable. [...] Si bien instrumentos internacionales, de los cuales Chile es parte, consagran la huelga como un derecho, estos dejan su regulación a la legislación interna y no existe razón para inferir de los mismos que el reemplazo está vedado. La cita, como hace el fallo, de países latinoamericanos que lo prohíben absolutamente, no hace más que acreditar que cada país se ha dado su regulación al respecto, como ha hecho nuestro país al contemplarlo reguladamente. De esta forma, interpretar las normas del reemplazo restrictivamente, amparado en el derecho a la huelga, es otorgar a este un alcance no consagrado en ningún instrumento o norma. ${ }^{109}$

Por último, en una línea muy similar a las anteriores, en una carta al director, un abogado experto laboral reitera las críticas a un fallo que — según él- es contradictorio, atenta a la certeza jurídica e invoca derechos de otros países. ${ }^{110}$

A partir de estas argumentaciones, nos podríamos preguntar ¿quién pone delante de su razonamiento sus preferencias políticas, los jueces de la Sala Laboral o los editores y autores de estos insertos en el periódico? ¿O es que acaso los jueces de la Sala Laboral deberían haberse abstenido de razonar, en el caso concreto, conforme al derecho internacional de los derechos humanos a propósito del derecho humano a la huelga, por qué, en sede política, se estaba discutiendo acerca de una posible reforma laboral? ¿La Corte Suprema invoca derechos de otros países o realiza un ejercicio

\footnotetext{
109 Ver "Fallo de la Corte Suprema que prohíbe reemplazo en huelga", La Tercera, viernes 12 de diciembre de 2014, en http:/ /www.latercera.com/noticia/opinion/editorial/2014/12/894608319-9-fallo-de-la-corte-suprema-que-prohibe-reemplazo-en-huelga.shtml, consulta del 12 de diciembre de 2014.

110 Aguayo, Cristian, "Prohibición del reemplazo en huelga", La Tercera, domingo 14 de diciembre de 2014, p. 8.
} 
de derecho comparado? Evidentemente que ambas ideas no me parecen similares. ¿Qué atenta más contra la certeza jurídica, la negativa sistemática a los derechos o la declaración clara y prístina del estándar mínimo de un derecho fundamental? En este contexto, el Presidente de la Corte Suprema ha reiterado la visión institucional respecto de la administración de justicia, al señalar: "[C]omo sociedad debemos preocuparnos de escuchar, de crear espacios de encuentro y entendimiento, de dar respuesta a todos los requerimientos de la gente, según lo he dicho, respetando todos los derechos y de todas las personas, como los principios de dignidad, libertad, igualdad, solidaridad y responsabilidad". ${ }^{111}$

Conviene recordar, en cuanto al experimento de implantación de un Estado neoliberal en Chile practicado durante la dictadura, que Karina Narbona ha sostenido que:

[e]l papel ejemplar y de laboratorio que desempeñó nuestro país en dictadura y que desempeña desde entonces, es quizás conocido, aunque no sobra hilar más fino en una de sus dimensiones: las 'siete modernizaciones’ que ideó José Piñera entre los años 1979 y 1981 fueron concebidas como hitos refundacionales y apuntaron al corazón de la fuerza de trabajo y a su integración social con el modelo laboral, educacional, de salud y previsión. Pocos saben que en ese proceso el primer paso y más relevante fue anular a los sindicatos ('Plan Laboral' de 1979) para habilitar a los empresarios a funcionar sin contrapeso social. Pues bien, 35 años después del Plan Laboral de 1979 y de haber consolidado la irrelevancia práctica del trabajador organizado después de la dictadura (hoy la tasa de sindicalización es solo del 14,2 \% y la de contratación colectiva del 8,4\%), estamos en condición de evaluar la desposesión que ello ha provocado desde la perspectiva 'privilegiada' que otorga habernos adelantado al neoliberalismo y contar con un modelo ya maduro. ${ }^{112}$

Y Narbona agrega una reflexión en torno a los derechos sociales, indicando que "[l]os derechos sociales, esos que hoy dependen de nuestra

\footnotetext{
111 Muñoz Gajardo, Sergio, “Derecho a ser oído”, El Mercurio, 17 de mayo de 2014.

112 Narbona, Karina, "Los súper ricos y la mercantilización de la vida”, El Mostrador, jueves 11 de diciembre de 2014, en http://www.elmostrador.cl/opinion/2014/12/11/ los-super-ricos-y-la-mercantilizacion-de-la-vida/, consulta del 12 de diciembre de 2014 .
} 
capacidad de pago y con los cuales la elite ha formado lucrativos negocios, no son otra cosa, de hecho, que el reconocimiento de requerimientos vitales para la humanidad que sostiene el sistema, son derechos a la vida. Y lo que producen estos sectores bajo dinámicas de acumulación por desposesión, es una negación de la vida (¿tendrá un efecto búmeran sobre la propia elite?)". ${ }^{113}$

Así, en cuanto a la labor argumentativa de los jueces de la Sala Laboral del máximo tribunal, se ha sostenido que

[e]sta nueva Sala ha vuelto a interpretar las normas laborales usando el principio 'pro operario'. Como el fallo que abrió la puerta a los funcionarios públicos para que recurran de tutela laboral a los Tribunales del Trabajo en caso de vulneración de derechos y garantías constitucionales por parte de los empleadores. Posibilidad que en la época de Valdés se aplicaba solo al mundo privado. O la resolución que reconoce nuevamente a las asignaciones por colación y movilización como parte de la base para realizar el cálculo de indemnizaciones por años de servicio frente a un despido. ${ }^{114}$

\section{Conclusiones}

El constitucionalismo global no se identifica con la apertura del derecho nacional y de sus jueces al derecho internacional de los derechos humanos. Esta apertura es una manifestación de ello, pero el constitucionalismo global no se agota allí. El constitucionalismo global es mucho más que la simple apertura del derecho nacional al DIDH, aun cuando, quizá, dicha apertura sea uno de sus rasgos más palpables. El constitucionalismo global es una manifestación moderna de una serie de procesos que tienden a identificar elementos estructurales de los Estados constitucionales en y para sociedades más amplias que exceden las fronteras de los Estados. Estas comunidades más globales que las nacionales habrían llegado a consensos en torno a elementos constitucionales comunes y compartidos, y entre cuyos pilares se cuentan la democracia, el Estado de derecho y los derechos humanos.

\footnotetext{
113 Ibíd.

114 Urquieta C., Claudia, "La nueva Sala Laboral de la Suprema que terminó con la era 'pro empresa' liderada por Patricio Valdés”, El Mostrador, 12 de diciembre de 2014, en http:/ / www.elmostrador.cl/pais/2014/12/12/la-nueva-sala-laboral-de-la-suprema-que-termino-con-la-era-pro-empresa-liderada-por-patricio-valdes/, consulta del 12 de diciembre de 2014.
} 
Así, en cuanto a estos últimos, los derechos humanos representarían valores y principios compartidos, en torno a cuyos mínimos irreductibles, necesarios para la sobrevivencia y la dignidad humana, las normas que se adoptan reflejarían un derecho común. El carácter reconocidamente universal de los derechos humanos reforzaría esta última idea. Por las características de las distintas comunidades en las diversas regiones en el mundo, esta comunidad de valores y principios tiende a mostrarse más nítidamente a nivel regional, primero, y luego, a nivel mundial. Así, el sistema interamericano de protección de los derechos humanos, tal como lo ha hecho el sistema europeo de protección de los derechos humanos, ha contribuido para que los países pertenecientes a tales sistemas identifiquen y vehiculen dichos estándares mínimos comunes. Por eso, se podría argumentar que, a partir de la actividad de los órganos de protección del sistema interamericano, en especial de la Corte IDH, en interacción con los distintos Estados partes, se han ido explicitando estándares mínimos comunes de derechos humanos. En este contexto, el control de convencionalidad lo único que hace es recordarles a los Estados — a cada uno de sus órganos, y en especial a los jueces- que tienen la obligación de respetar y cumplir con sus obligaciones internacionales conforme con los estándares mínimos comunes de derechos humanos que se han ido construyendo en el sistema interamericano, del que voluntariamente forman parte.

La operacionalización del control de convencionalidad en el nivel interno de los Estados sería, en consecuencia, una vía idónea en el proceso de construcción de un ius commune interamericanum. Si recordamos que los derechos humanos se erigen como valores y normas de carácter constitucional, entonces, se trataría de un ius constitutionale commune interamericanum. Cabe así mismo resaltar que este ius commune interamericanum no es el reflejo de la visión unilateral de los órganos del sistema de protección de derechos humanos, sino el fruto de un diálogo derivado de la interacción entre los órganos del sistema con los órganos del Estado. En efecto, si los órganos del Estado otorgan un estándar de protección más alto o menos restrictivo de sus derechos al individuo o a la comunidad, entonces, por el principio pro homine, este estándar es el que va a primar. Este principio, que en el fondo es un criterio racional de razonamiento, es el eje articulador de la coherencia de todo el sistema de derechos humanos. Y en este mismo sentido, el ius commune de los derechos humanos en América no se va a erigir como un derecho diverso del ius commune de los derechos humanos europeo. Al contrario, ambos sistemas y órganos se retroalimentan, se complementan e interactúan a través de un diálogo fructífero, forjando 
estándares mínimos comunes. Y, en este ámbito acotado de los derechos humanos, el ius constitutionale commune interamericanum sería una contribución, una piedra más, en el proceso de consolidación de un constitucionalismo global, del cual los derechos humanos son una pieza clave.

En este trabajo, a través de trascendentes casos jurisprudenciales nacionales sobre el derecho humano a la huelga, hemos intentado mostrar ejemplos nacionales de control de convencionalidad. Estos casos son relevantes porque en el actualmente disminuido catálogo constitucional chileno de derechos económicos, sociales y culturales, el derecho a huelga casi no figura. Pero además, estos casos son destacables, puesto que en nuestra opinión son ejemplos de control de convencionalidad realizado por la Corte Suprema respecto del derecho a huelga. En efecto, en estas sentencias, la Corte Suprema contrasta la norma legal y constitucional con las normas convencionales vinculantes para el Estado. A partir de las disposiciones convencionales, e interpretando las normas legales conforme a las normas convencionales, la Corte concluye el estándar mínimo en materia de derecho a huelga, y concluye que el reemplazo de trabajadores en huelga, ya sea por otros de la misma empresa o nuevos contratados, no procede. La realización del control de convencionalidad por parte de la Corte Suprema en los referidos casos del derecho a huelga se inserta, en nuestra visión, en la línea de construcción de un sistema integrado y coherente de derechos humanos y por esta vía, en cuanto normas de carácter constitucional, en un ius constitutionale commune y un constitucionalismo global.

\section{Referencias bibliográficas}

Aguilar Cavallo, Gonzalo, "La Corte Suprema y la aplicación del derecho internacional: un proceso esperanzador", Estudios Constitucionales, 2009, 7, (1), pp. 91-136.

Asamblea General, En aras de la justicia: un programa de acción para reforzar el estado de derecho en los planos nacional e internacional, informe del Secretario General, Doc. N.U. A/66/749, 16 de marzo de 2012.

Brito Melgarejo, Rodrigo, "El uso de sentencias extranjeras en los tribunales constitucionales. Un análisis comparativo", InDret Revista para el Análisis del Derecho, 2002, (2), pp. 1-22.

Cançado Trindade, Antonio Augusto, Tratado de direito internacional dos direitos humanos, vol. I, Editor Fabris, Porto Alegre, 1997. 
Carbonell, Miguel, “Derecho a migrar", en Fix-Zamudio, Héctor \& Valadés, Diego, Instituciones sociales en el constitucionalismo contemporáneo, Instituto de Investigaciones Jurídicas, México, 2011.

Cardoso Campos, Bárbara Pincowsca, "Controle de convencionalidade: aproximação entre o direito internacional é o constitucionalismo?", Revista do Instituto Brasileiro de Direitos Humanos, 2013, 13, (13), pp. 47-58.

Castilla Juárez, Karlos A., "Control de convencionalidad interamericano: una mera aplicación del derecho internacional", Derecho del Estado, 2014, (33).

CDH, Informe anual sobre derechos humanos en Chile 2014, Ediciones Diego Portales, Santiago, 2014.

Chevallier, Jacques, «Mondialisation du droit ou droit de la mondialisation», en Morand, Charles-Albert (Dir.), Le droit saisi par la mondialisation, Bruylant, Bruxelles, 2001.

Comité de Derechos Económicos, Sociales y Culturales, Observación General No 3, La indole de las obligaciones de los Estados partes, quinto período de sesiones (1990).

Convenio 87 de la Organización Internacional del Trabajo Convenio sobre la Libertad Sindical y la Protección del Derecho de Sindicación de 1948.

Craig, Paul, "Constitution, constitutionalism and the European Union", European Law Journal, 2001, 7, (2), pp. 125-150.

Delmas-Marty, Mireille, «Les processus de mondialisation du droit», en Morand, Charles-Albert (Dir.), Le droit saisi par la mondialisation, Bruylant, Bruxelles, 2001.

Dulitzky, Ariel, "Los tratados de derechos humanos en el constitucionalismo iberoamericano", en Buergenthal, Thomas \& Cançado Trindade, A. A. (Comps.), Estudios especializados de derechos humanos, tomo I, Instituto Interamericano de Derechos Humanos, San José, 1996.

Dutheillet de Lamothe, Olivier, «Contrôle de constitutionnalité et contrôle de conventionnalité», en Mélanges en l'honneur de Daniel Labetoulle, Dalloz, Paris, 2007.

Epiney, Astrid, «Européanisation et mondialisation du droit: convergences et divergences», en Morand, Charles-Albert (Dir.), Le droit saisi par la mondialisation, Bruylant, Bruxelles, 2001.

Ferrajoli, Luigi, "Más allá de la soberanía y de la ciudadanía: un constitucionalismo global", Isonomía, 1998, (9). 
Ferreira Mendes, Gilmar, "La doctrina de un derecho común iberoamericano: consideraciones en homenaje a la doctrina de Peter Häberle y su influencia en Brasil", Revista de Derecho Constitucional Europeo, 2009, 6, (11), pp. 65-86.

Ferrer Mac-Gregor, Eduardo, “Interpretación conforme y control difuso de convencionalidad. El nuevo paradigma para el juez mexicano", Estudios Constitucionales, 2011, 9, (2), pp. 531-622.

Fix-Zamudio, Héctor, "El derecho internacional de los derechos humanos en las constituciones latinoamericanas y en la Corte Interamericana de Derechos Humanos", Revista Latinoamericana de Derecho, 2004, I, (1), pp. 141-180.

Gernigon, Bernard; Odero, Alberto \& Guido, Horacio, Principios de la OIT sobre el derecho de huelga, Oficina Internacional del Trabajo, Ginebra, 2000.

Gomes Canotilho, José Joaquim, "Principios y 'nuevos constitucionalismos': el problema de los nuevos principios", Revista de Derecho Constitucional Europeo, 2010, 7, (14), pp. 321-364.

Gómez Gamboa, David Augusto, "Hacia un ius constitutionale commune americanum”, Frónesis, 2013, 20, pp. 447-466.

Gros Espiell, Héctor, "La dignidad humana en los instrumentos internacionales sobre derechos humanos", Anuario de Derechos Humanos, 2003, 4, pp. 193-223.

Gros Espiell, Héctor, "Una mirada actual a la Declaración Universal de los Derechos Humanos", Estudios, 2009, vII, (91), pp. 69-87.

Häberle, Peter, "Derecho constitucional común europeo", Revista de Estudios Políticos, 1993, (79).

Häberle, Peter, El Estado constitucional, traducción de Héctor Fix-Fierro, UNAM-Instituto de Investigaciones Jurídicas, México, 2003.

Herz, John, "Rise and demise of the territorial State", World Politics, 1957, 9. Hillgruber, Christian, "La integración del derecho internacional y del derecho de la Unión Europea en el ordenamiento constitucional alemán”, Revista de Derecho Constitucional Europeo, 2004, (1), pp. 115-138.

ICJ, Reservations to the Convention on the Prevention and Punishment of the Crime of Genocide, Advisory opinion of May 28 ${ }^{\text {th }}, 1951$, ICJ Reports 1951.

INDH, Informe anual sobre la situación de los derechos humanos en Chile 2014, Santiago, 2014.

Jinesta, Ernesto, "La construcción de un derecho administrativo común interamericano: reformulación de las fuentes del derecho administrativo con la constitucionalización del derecho internacional de 
los derechos humanos", Revista Iberoamericana de Derecho Público y Administrativo, 2011, 11, (11), pp. 1-16.

Kritsch, Raquel, "Fundamentos históricos e teóricos da noçào de soberanía: a contribuçao dos 'Papas juristas' do século XIII', Estudios Históricos, 2010, 23, (46), pp. 261-279.

L'Heureux-Dubé, Claire, "The importance of dialogue: globalization and the international impact of the rehnquist court", Tulsa Law Journal, 34, (1), pp. 15-40.

Mahiou, Ahmed, «Le droit international ou la dialectique de la rigueur et de la flexibilité. Cours général de droit international public», Recueil des Cours, 2008, 337.

Manga Fombad, Charles, "The context of justice in Africa: emerging trends and prospects", in Rethinking the role of law and justice in Africa's development, United Nations Development Programme, 2013.

Martin Retortillo Baquer, Lorenzo; Ferrer Mac-Gregor, Eduardo \& Herrera García, Alfonso (Coords.), Diálogo jurisprudencial en derechos bumanos. Entre tribunales constitucionales y cortes internacionales, Tirant lo Blanch, Madrid, 2013.

Nash Rojas, Claudio, "El control de convencionalidad: incógnitas, desafíos y perspectivas", en Bazán, Víctor \& Nash, Claudio (Eds.), Justicia constitucionaly derechos fundamentales. El control de convencionalidad, Konrad Adenauer Stiftung E.V., Bogotá, 2012, pp. 57-70.

Neves, Marcelo, Transconstitucionalismo, $1^{\mathrm{a}}$ ed., WMF: Martins Fontes, São Paulo, 2009.

Nogueira Alcalá, Humberto, "Derechos fundamentales, bloque constitucional de derechos, diálogo interjurisdiccional y control de convencionalidad", Ubijus Editorial, México, 2014.

Organización Internacional del Trabajo, Libertad sindical. Recopilación de decisiones y principios del Comité de Libertad Sindical del Consejo de Administración de la OIT, $5^{a}$ edición revisada, Oficina Internacional del Trabajo, Ginebra, 2006.

Pampillo Baliño, Juan Pablo, "Derecho comunitario y ius commune americano: dos asignaturas pendientes para las ciencias jurídicas de nuestro continente", Foro, Revista de Derecho, 2012, (18), pp. 5-29.

Peters, Anne, "The merits of global constitutionalism", Indiana Journal of Global Legal Studies, 2009, 16, (2), pp. 397-411.

Ramos, André de Carvalho, Processo internacional de direitos humanos, $2^{\mathrm{a}}$ ed., Saraiva, Sao Paulo, 2012. 
Reina García, Óscar M., "Las cláusulas de apertura o reenvío hacia fuentes externas previstas en la Constitución colombiana, como criterio para delimitar el contenido del bloque de constitucionalidad", Revista Derecho del Estado, 2012, (29), pp. 175-214.

Salvioli, Fabián, "Un análisis desde el principio pro persona sobre el valor jurídico de las decisiones de la Comisión Interamericana de Derechos Humanos", en En defensa de la Constitución: un homenaje a Germán Bidart Campos, Ediar, Buenos Aires, 2003.

Santolaya, Pablo, "La apertura de las constituciones a su interpretación conforme a los tratados internacionales", en Martin Retortillo Baquer, Lorenzo; Ferrer Mac-Gregor, Eduardo \& Herrera García, Alfonso (Coords.), Diálogo jurisprudencial en derechos humanos. Entre tribunales constitucionales y cortes internacionales, Tirant lo Blanch, Madrid, 2013.

Sarlet, Ingo, "Posibilidades y desafíos de un derecho constitucional común latinoamericano", Revista de Derecho Constitucional Europeo, 2009, 6, (11), pp. 87-134.

Teruel Lozano, Germán M., "El Tribunal Constitucional ante el principio de primacía del derecho comunitario", Anales de Derecho, Universidad de Murcia, 2006, (24), pp. 319-352.

Tomuschat, Christian, "International law: ensuring the survival of mankind on the eve of a new century. General course on public international law”, Recueil des Cours, 1999, 281.

Von Bogdandy, Armin, "Constitutionalism in international law: comment on a proposal from Germany", Harvard International Law Journal, 2006, 47, (1).

Von Bogdandy, Armin, "Ius constitutionale commune latinoamericanum. Una aclaración conceptual”, en Von Bogdandy, Armin; Fix-Fierro, Héctor \& Morales Antoniazzi, Mariela (Coords.), Ius constitutionale commune en América Latina, Instituto de Investigaciones Jurídicas, Instituto Max Planck de Derecho Público Comparado y Derecho Internacional, Instituto Iberoamericano de Derecho Constitucional, UNAM-IIJ, México, 2014.

\section{Jurisprudencia}

Corte de Apelaciones de Rancagua, Homicidio simple de Luis Almonacid Arellano, recurso de apelación, Rol No 103-2011, 14 de enero de 2013. 
Corte Interamericana de Derechos Humanos, Caso Almonacid Arellano y otros vs. Chile, sentencia del 26 de septiembre de 2006, Serie C $\mathrm{N}^{\mathrm{o}} 154$.

Corte Interamericana de Derechos Humanos, Caso Atala Riffo y Niñas vs. Chile, sentencia del 24 de febrero de 2012, Serie C Nº 254.

Corte Interamericana de Derechos Humanos, Caso Cabrera García y Montiel Flores vs. México, sentencia del 26 de noviembre de 2010, Serie C No 209.

Corte Interamericana de Derechos Humanos, Caso de la Corte Suprema de Justicia (Quintana Coello y otros) vs. Ecuador, sentencia del 23 de agosto de 2013, Serie C No 266.

Corte Interamericana de Derechos Humanos, Caso Myrna Mack Chang vs. Guatemala, sentencia del 25 de noviembre de 2003, Serie C No 101.

Corte Interamericana de Derechos Humanos, Caso Radilla Pacheco vs. México, sentencia del 23 de noviembre de 2009, Serie C No 209.

Corte Interamericana de Derechos Humanos, Caso Tibi vs. Ecuador, sentencia del 7 de septiembre de 2004.

Corte Interamericana de Derechos Humanos, Caso Trabajadores cesados del Congreso (Aguado Alfaro y otros) vs. Perú, sentencia del 24 de noviembre de 2006, Serie C No 158.

Corte Interamericana de Derechos Humanos, Opinión Consultiva OC17/2002 del 28 de agosto de 2002, solicitada por la Comisión Interamericana de Derechos Humanos sobre la condición jurídica y derechos humanos del niño.

Corte Interamericana de Derechos Humanos, Supervisión de cumplimiento de sentencia en el caso Gelman vs. Uruguay, resolución de la Corte Interamericana de Derechos Humanos del 20 de marzo de 2013.

Corte Internacional de Justicia, Legality of the use by a State of nuclear weapons in armed conflict, Advisory opinion of 8 July 1996, ICJ Reports 1996.

Corte Suprema, Amparo de presos discapacitados, Rol No 26.492-2014, 30 de octubre de 2014.

Corte Suprema, Inspección Comunal del Trabajo Norte Chacabuco con Carvajal Empaques S.A., procedimiento de tutela laboral, Rol $\mathrm{N}^{\circ}$ 10.444-2014, 29 de enero de 2015.

Corte Suprema, Molina Aguilera con Comercial Sepmo y Cía. Ltda. y otros, Rol N 10.139-2013, sentencia de fecha 10 de junio de 2014.

Corte Suprema, Sindicato de Trabajadores de Empresa Promolinks S.A., procedimiento de tutela laboral, Rol No 3.514-2014, sentencia del 4 de diciembre de 2014. 
Juzgado de Letras del Trabajo de Concepción, Sentencia Rol No 1790-10, 4 de octubre de 2011.

Tribunal Constitucional de Chile, Requerimiento de inaplicabilidad por inconstitucionalidad 'Subsecretaría Interior con Consejo para la Transparencia', de que conoce la Corte de Apelaciones de Santiago, bajo el Rol No 6704-2011, sentencia de fecha 11 de septiembre de 2012.

Tribunal Constitucional de Chile, Requerimiento de inaplicabilidad por inconstitucionalidad ante el Juzgado de Letras de Concepción, Rol No 1790-10, sentencia de fecha 4 de octubre de 2011.

Tribunal de Justicia de la Comunidad Europea, Amministrazione delle Finanze dello Stato y SpA Simmenthal, sentencia del Tribunal de Justicia del 9 de marzo de 1978, asunto 106/77.

\section{Documentos electrónicos}

"Fallo de la Corte Suprema que prohíbe reemplazo en huelga", La Tercera, viernes 12 de diciembre de 2014, en http://www.latercera.com/ noticia/opinion/editorial/2014/12/894-608319-9-fallo-de-la-cortesuprema-que-prohibe-reemplazo-en-huelga.shtml, consulta del 12 de diciembre de 2014.

"Masacre de la Escuela Santa María de Iquique", en http:/ / www.memoriachilena.cl/602/w3-article-3604.html\#presentacion, consulta del 15 de diciembre de 2014.

Angulo Jacobo, Luis Fernando, Constitucionalismo global, en https://www. scjn.gob.mx/Transparencia/Lists/Becarios/Attachments/44/Becarios_044.pdf, consulta del 20 de noviembre de 2014.

Contreras, Pablo, "Control de convencionalidad fuerte y débil: parte I", Diario Constitucional, 17 de agosto de 2012, en http:// diarioconstitucional.cl/articulos/control-de-convencionalidad-fuerte-y-debilparte-i/, consulta del 12 de diciembre de 2014.

Dutheillet de Lamothe, Olivier, «Contrôle de conventionnalité et contrôle de constitutionnalité en France», en http://www.conseil-constitutionnel.fr/conseil-constitutionnel/root/bank_mm/pdf/Conseil/ madrid_odutheillet_avril_2009.pdf, consulta del 12 de diciembre de 2014.

Narbona, Karina, "Los súper ricos y la mercantilización de la vida”, El Mostrador, jueves 11 de diciembre de 2014, en http:/ / www.elmostrador.cl/opinion/2014/12/11/los-super-ricos-y-la-mercantilizacionde-la-vida/, consulta del 12 de diciembre de 2014. 
Organización Internacional del Trabajo, "Libertad de asociación y la libertad sindical y el reconocimiento efectivo del derecho de negociación colectiva", en http:/ /ilo.org/declaration/principles/freedomofassociation/lang--es/index.htm, consulta del 12 de diciembre de 2014.

Urquieta C., Claudia, "La nueva Sala Laboral de la Suprema que terminó con la era 'pro empresa' liderada por Patricio Valdés", El Mostrador, 12 de diciembre de 2014, en http://www.elmostrador.cl/ pais/2014/12/12/la-nueva-sala-laboral-de-la-suprema-que-terminocon-la-era-pro-empresa-liderada-por-patricio-valdes/, consulta del 12 de diciembre de 2014.

\section{Otros documentos}

"Supremazo' sobre reemplazo en huelga", El Mercurio, domingo 7 de diciembre de 2014, p. A3.

Aguayo, Cristian, "Prohibición del reemplazo en huelga", La Tercera, domingo 14 de diciembre de 2014.

Muñoz Gajardo, Sergio, "Derecho a ser oído", El Mercurio, 17 de mayo de 2014. 